\title{
UNA EVALUACIÓN SOCIAL DE LA INTRODUCCIÓN DE LA TELEFONÍA IP SOBRE BANDA ANCHA
}

\author{
Alexander Galetovic \\ y Ricardo Sanhueza
}

\begin{abstract}
Este trabajo estima el cambio del excedente social si se introduce la telefonía IP sobre banda ancha. De un lado, quienes ya tienen una conexión de banda ancha pagarían menos. Del otro lado, la migración de clientes desaprovecharía economías de escala en la telefonía tradicional.

Usando el modelo aplicado en la última fijación tarifaria se concluye que la telefonía IP sobre banda ancha haría caer el bienestar social, pero esta conclusión no es robusta. Si el error de medición del mode-
\end{abstract}

Alexander Galetovic. Profesor de la Universidad de los Andes e Investigador del Centro de Estudios Públicos.

Ricardo Sanhueza. Profesor de la Universidad de los Andes.

* Este trabajo fue financiado por Telefónica CTC S.A. y forma parte de un proyecto de investigación sobre la economía de las telecomunicaciones bajo el cual Telefónica CTC S.A. renunció a su derecho a revisión. Por lo tanto, las opiniones expresadas son nuestras, y no comprometen a Telefónica CTC S.A. Agradecemos la ayuda que nos prestó Claudio Lorca, quien corrió el modelo tarifario y el de telefonía IP sobre banda ancha; las didácticas exposiciones sobre telefonía IP de Omar Cancino y Luis Vilches; los comentarios de Patricio Cáceres, Ronald Fischer, Andrés Gómez-Lobo, José Tomás Morel, Ricardo Rainieri, Humberto Soto, un árbitro anónimo y los participantes en seminarios en el Centro de Estudios Públicos, Ilades, el Instituto Libertad y Desarrollo, el Centro de Economía Aplicada, la Universidad Católica y el Primer Congreso Iberoamericano de Regulación Económica; y una útil conversación con Alejandro Ulloa. Los datos de costos nos fueron proporcionados por Telefónica CTC S.A.

Estudios Públicos, 103 (invierno 2006). 
lo de costos fuera del orden de $10 \%$, no se podrían rechazar la hipótesis nula que uno elija.

Sin embargo, la telefonía IP sobre banda ancha tiene efectos distributivos importantes. Si el 5\% del tráfico emigra, los usuarios que permanezcan en la telefonía tradicional deberían pagar US\$1,15 millones más cada mes (\$213 más por línea), mientras que quienes emigren pagarían US\$798.815 menos (\$12.912 menos por línea). Si emigra el 25\% del tráfico, estas cifras crecen a, respectivamente, US\$4,77 millones más mensuales (\$976 por línea), mientras que quienes emigren pagarían US\$3,08 millones menos (\$5.226 menos por línea).

\section{Introducción}

L

os cambios tecnológicos permiten prestar servicios telefónicos de voz utilizando las conexiones de banda ancha. Para ello el usuario debe contar con una conexión con un proveedor de Internet, ya sea a través del par de cobre de una línea de teléfono local o bien un cable coaxial. Es por esto que la Subsecretaría de Telecomunicaciones (Subtel) pensó normar el servicio de voz sobre banda ancha. Un nuevo reglamento hubiera definido una concesión de servicio público de telecomunicaciones de voz sobre banda ancha, la que hubiera permitido interconectar a empresas de telefonía IP sobre banda ancha con las redes telefónicas públicas (Subtel, 2004a). Este trabajo evalúa socialmente la introducción de la voz sobre banda ancha.

Generalmente, se suele pensar que su introducción sólo trae beneficios, principalmente por una competencia más intensa y porque se trata de progreso tecnológico. Este trabajo muestra que tal conclusión debe matizarse. Una razón es que la voz sobre banda ancha sigue usando la red de acceso de la telefonía tradicional; en realidad sólo sustituye a la conmutación y transmisión. También es cierto que para prestar servicios de telefonía IP sobre banda ancha es necesario invertir en equipos. Por último, la migración de clientes y tráfico hacia la telefonía IP sobre banda ancha aumenta los costos medios de las empresas telefónicas tradicionales y, con ello, las tarifas que las autofinancian. Así, y aunque esto no forma parte de una evaluación social, a los efectos de eficiencia se les deben agregar otros distributivos: ganan aquellos clientes que emigran a la telefonía IP sobre banda ancha, y pierden quienes permanecen en la compañía tradicional. 
Para estudiar los efectos de eficiencia examinamos cómo varía el excedente social neto con la introducción de la telefonía IP sobre banda ancha. Nuestro trabajo es, básicamente, una evaluación social del proyecto introducción de la telefonía IP sobre banda ancha. Dado el número de minutos de telefonía fija actualmente cursados y de usuarios conectados a la red, calculamos el costo total de cursar esas llamadas por una empresa de telefonía fija eficiente ${ }^{1}$. Luego introducimos la telefonía IP sobre banda ancha, y calculamos el costo de cursar esas mismas llamadas, ahora en parte por una red fija eficiente ajustada al menor tráfico y número de líneas activas y, en parte, por la red IP, ambas interconectadas.

Como ya se dijo, mostraremos que el resultado depende de dos efectos contrapuestos. De un lado, la telefonía IP sobre banda ancha beneficia a quienes están dispuestos a pagar por una conexión de banda ancha, porque pueden cambiarse a un proveedor de telefonía IP sobre banda ancha y llamar pagando menos. Del otro lado, sin embargo, la migración de clientes hacia la telefonía IP sobre banda ancha aumenta el costo medio de la telefonía tradicional, porque se desaprovechan economías de escala por la caída del número de líneas activas y del tráfico.

¿Se puede ir más allá y cuantificar ambos efectos? Utilizaremos datos del costo de la telefonía IP sobre banda ancha y de las economías de escala en la red de telefonía tradicional, proporcionados por Telefónica CTC, para hacerlo. Estos ejercicios indican que el bienestar social caerá con la introducción de la telefonía IP sobre banda ancha. Si el 5\% del tráfico emigrase hacia la red IP, esta pérdida es del orden de los US\$351.000 mensuales y podría llegar a US\$1,69 millones mensuales si el 25\% del tráfico emigrase hacia la telefonía IP sobre banda ancha.

Sin embargo, tal conclusión no es robusta, en el sentido que si el modelo tarifario estuviera sujeto a un pequeño error de medición, del orden del 10\%, no se podría rechazar la hipótesis nula de que la introducción de la telefonía IP sobre banda ancha dejará igual o incluso aumentará el bienestar social. Al mismo tiempo, si la hipótesis nula fuera la introducción de la telefonía IP sobre banda ancha disminuye el bienestar social, bastaría un pequeño error de medición, de orden de magnitud similar, para que no se pueda rechazar. El punto de fondo es que, en las condiciones actuales, el cambio del bienestar social es incierto.

Lo que sí se puede concluir con razonable confianza es que los efectos distributivos de la introducción de la telefonía IP sobre banda ancha son importantes. Grosso modo, ésta implica favorecer a un número pequeño

${ }^{1}$ En el sentido que le da al término la Ley de Telecomunicaciones. 
de usuarios quienes, aun antes de la introducción de la telefonía IP sobre banda ancha, están dispuestos a pagar por una conexión de banda ancha; y perjudicar a un número grande de usuarios — aquellos que no emigrarán hacia la telefonía IP sobre banda ancha- por un monto individualmente pequeño. Estimamos que si el 5\% del tráfico emigra, los usuarios que permanezcan en la telefonía tradicional deberían pagar US\$1,15 millones más mensuales (\$213 más por línea), mientras que quienes emigren pagarían US\$798.815 menos (\$12.912 menos por línea) ${ }^{2}$. Si emigra el 25\% del tráfico, estos montos crecen a, respectivamente, US $\$ 4,77$ millones más mensuales (\$976 más por línea), mientras que quienes emigren pagarían US\$3,08 millones menos (\$5.226 menos por línea) ${ }^{3}$. La pérdida impuesta a cada usuario que permanece en la telefonía fija depende de cuánto tráfico se traslade hacia la telefonía IP sobre banda ancha: mientras mayor sea el traslado, mayor es el aumento del costo medio.

Es importante delimitar el ámbito de nuestro trabajo y los supuestos que haremos en camino hacia nuestros resultados. Para comenzar, se trata de una evaluación social de la introducción de voz sobre banda ancha. Supone, por tanto, y valga la redundancia, que la telefonía IP se presta mediante una conexión de banda ancha. Así, la voz del usuario se paquetiza en su hogar, se envía por la red de datos tal como un correo electrónico o una conexión con una página web, y el proveedor del servicio de banda ancha la entrega en el ISP del proveedor de telefonía IP. Más aún, el proveedor de telefonía IP no instala electrónica entre el adaptador telefónico en la casa del usuario (el aparato que transforma la voz en paquetes) y su ISP de telefonía IP. Estos son los servicios que Subtel quiere normar por medio de las Concesiones de Servicio Público de Telecomunicaciones de Voz sobre Banda Ancha.

Para evitar confusiones, es muy importante distinguir la telefonía IP sobre banda ancha de las restantes formas de telefonía IP. La primera es aquella que han adoptado una serie de grandes usuarios tales como bancos o universidades. Estos clientes son servidos por un proveedor de telefonía IP que aprovecha una red de datos y la usa para dar servicio telefónico. De esta forma, el tráfico interno de voz nunca deja esta red privada. El tráfico externo, por su parte, es trasladado por una red privada y el proveedor de telefonía IP lo conmuta y entrega en los PTR de las restantes empresas telefónicas locales, de larga distancia o móviles. Esta forma de telefonía IP

2 Todos los montos son sin IVA.

${ }^{3}$ Este cálculo supone que el mercado de telefonía IP sobre banda ancha es competitivo. Si no lo fuera, lo reportado corresponde a la suma de la ganancia del consumidor y la renta que obtiene el proveedor de telefonía IP sobre banda ancha. 
es irrelevante para evaluar la introducción de la voz sobre banda ancha, porque no compite con ella - los usuarios que optan por este tipo de telefonía no acceden a Internet mediante un ISP proveedor de banda ancha-

En segundo lugar, las telefónicas locales podrían sustituir sus conmutadores y enlaces de transmisión, los que funcionan con el protocolo TDM, por tecnología IP que paquetiza las llamadas telefónicas y las envía por una red de datos privada y cerrada ${ }^{4}$. Se trata, entonces, de sustituir una tecnología de conmutación y transmisión tradicional por una nueva. Sin embargo, esto no cambia el hecho de que el tráfico de voz se hace por una red privada y cerrada.

A pesar de que la red tradicional de telefonía pública local se puede reemplazar por una red de datos y los así llamados soft switches IP, en el trabajo suponemos que la conmutación y la transmisión siguen haciéndose en el protocolo tradicional TDM. Lo hacemos por dos razones. Primero, es una pregunta abierta si la nueva tecnología es la que debiera elegir una empresa eficiente de telefonía fija; por el momento, la empresa eficiente ocupa la tecnología tradicional y será la próxima fijación tarifaria la que zanjará esta cuestión. Segundo, y más importante, si una red de telefonía local IP fuera más eficiente, la evaluación social de la introducción de la telefonía IP sobre banda ancha es igual. En efecto, la telefonía IP sobre banda ancha le saca tráfico a la red de telefonía tradicional y ésta pierde economías de escala. La evaluación social consiste en calcular el costo de cursar todas las llamadas por una empresa eficiente que esta vez conmuta IP; luego se introduciría la voz sobre banda ancha; y finalmente se calcularía el cambio del costo de la empresa eficiente que utiliza tecnología IP. El punto es que el efecto de la telefonía IP sobre banda ancha es el mismo, independientemente de qué tecnología ocupe la telefónica tradicional.

Antes de seguir, tres observaciones o advertencias al lector. La novedad del trabajo es afirmar que la introducción de una nueva tecnología no mejora necesariamente el bienestar. Por lo tanto, en los cálculos que siguen hemos tratado de sesgar los resultados en favor de la voz sobre banda ancha. Así, en la duda, adoptamos el supuesto más favorable para la voz sobre banda ancha.

En segundo lugar, es importante mencionar que existe mucha confusión acerca de qué es exactamente la voz sobre banda ancha, cómo se diferencia de otras formas de telefonía IP y qué activos se ocupan para proveerla. Con las limitaciones evidentes de personas que no son ni cerca-

${ }^{4}$ TDM es el acrónimo de time division multiplexing. Una explicación didáctica de esta tecnología se encuentra en Sutton (1998, p. 138) y en Galetovic y Sanhueza (2006). 
namente expertas en redes, en la sección 2 hemos tratado de explicar de la mejor manera que nos ha sido posible en qué consiste la voz sobre banda ancha. Lo hicimos porque creemos que para discutir con provecho la economía del problema es indispensable entender un par de cuestiones técnicas que la condicionan. Por eso, al lector con poco tiempo le sugerimos, a lo menos, no saltarse la sección 2.

Por último, nuestro fin no es ni apoyar ni oponernos a la voz sobre banda ancha. Creemos sano, en todo caso, someterla a una evaluación económica, y establecer cuáles son sus consecuencias, tanto de eficiencia como distributivas. Las autoridades políticas se encargarán de tomar las decisiones.

El resto del trabajo se organiza como sigue. En la sección 2 se explica de manera breve y esquemática cómo se provee telefonía IP sobre banda ancha utilizando la red de acceso de una operadora de telefonía fija. En la sección 3 se presenta un modelo para analizar el efecto sobre el bienestar social cuando se introduce la telefonía IP sobre banda ancha. La sección 4 presenta los resultados teóricos y la sección 5 cuantifica los efectos. La sección 6 concluye.

\section{La telefonía IP sobre banda ancha}

Antes de analizar el efecto económico de la introducción de la telefonía IP sobre banda ancha conviene describir brevemente cómo se ofrece este servicio a los clientes conectados a una red de telefonía fija. Para ello resulta conveniente entender cuáles son los componentes básicos de una red de telefonía local, algunas características de su función de costos, y cómo se proveen servicios de banda ancha montado sobre esa red.

La red de telefonía local. La red de telefonía local permite comunicar a dos o más usuarios conectados a ella. Como se muestra en la Figura $N^{0} 1$, en esta red se pueden distinguir tres componentes esenciales: una red de acceso que conecta a cada suscrito con su central; la conmutación, que identifica el destino de cada llamada y establece el enlace físico que se necesita para que hablen dos suscritos; y la red de transporte, que conecta a las centrales telefónicas entre sí, Providencia y Santiago en la Figura No 1.

La red de acceso está conformada por pares de cobre que conectan los teléfonos de los usuarios con su central telefónica. Cada par de cobre sirve a un solo usuario y su costo no depende del nivel de tráfico sino de la densidad y la penetración. Ello es así porque, todo lo demás constante, cuando ya existe una red de acceso desplegada, un aumento del número de 
FIGURA No $1: \quad$ LA RED DE TELEFONÍA LOCAL

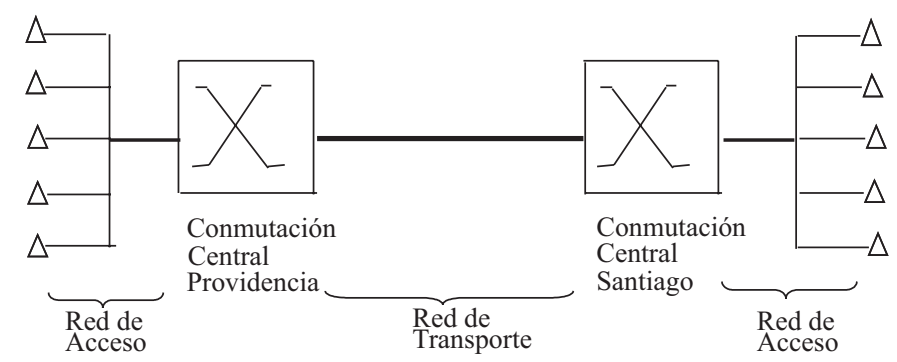

La figura muestra la configuración básica de una red de telefonía local que sirve dos áreas de una ciudad, cada una de ellas atendida por su central telefónica. Los teléfonos de los abonados están conectados a su respectiva central por medio de pares de cobre que conforman la red de acceso. En cada una de las centrales telefónicas se albergan los equipos que se utilizan para conmutar las llamadas, y las centrales están conectadas entre sí por medio de enlaces que conforman la red de transporte.

abonados conectados permite prorratear esa inversión en un mayor número de clientes y el costo medio disminuye. Por otra parte, la red de acceso se despliega considerando a los clientes potenciales en un área de servicio, por lo que conectar más usuarios en esa misma área no requiere de inversiones adicionales. Por lo tanto, el costo medio de la red de acceso desplegada en un área determinada disminuye a medida que aumenta la penetración —el porcentaje de clientes potenciales que efectivamente se conectan-. Cuando la densidad y la penetración son mayores la infraestructura ya desplegada se utiliza más intensamente, y el costo medio por usuario conectado disminuye.

La conmutación y la red de transporte, en cambio, son recursos compartidos cuya dimensión se elige para servir el tráfico de punta. Si bien la inversión en conmutadores y equipos de transmisión es proporcional al tráfico que sirve la red, otras inversiones tales como las edificaciones, equipos de energía y clima y la canalización de la fibra óptica son indivisibles. Por lo tanto, existen economías de escala respecto del nivel de tráfico que cursa la red. Si el tráfico cae, aumenta el costo medio por minuto de conmutación y transmisión.

La provisión de banda ancha por medio de la red de acceso. Los clientes de la red de telefonía local pueden recibir servicios de banda ancha utilizando el mismo par de cobre que conecta su teléfono a la central telefó- 
nica. Para ello, y como se muestra en la Figura $N^{\circ}$ 2, la empresa de banda ancha debe instalar electrónica en los extremos del par de cobre. En la casa del abonado se instala un módem (ADSL). Los splitters permiten que los datos utilicen parte del espectro del par de cobre para trasladar paquetes de bits hasta un concentrador de señales de alta velocidad (DSLAM) instalado en la central telefónica. Ello permite conectar el computador con la red de datos y usar el par de cobre para comunicaciones de voz tradicional y datos simultáneamente.

Para evitar confusiones es muy importante notar que el tráfico de datos no es procesado por la red de conmutación ni tampoco utiliza la red de transporte de la red telefónica local (la nube RTPC en la Figura $\mathrm{N}^{\circ}$ 2), sino que utiliza una red de datos independiente que le conecta a un proveedor de servicios de Internet (ISP). De esta manera una empresa puede ofrecer servicios de banda ancha a los clientes de la red telefónica conectando su red de datos a la red de acceso local y a un proveedor de servicios de Internet.

FIGURA N ${ }^{\circ}$ 2: $\quad$ BANDA ANCHA SOBRE LA RED DE TELEFONÍA LOCAL

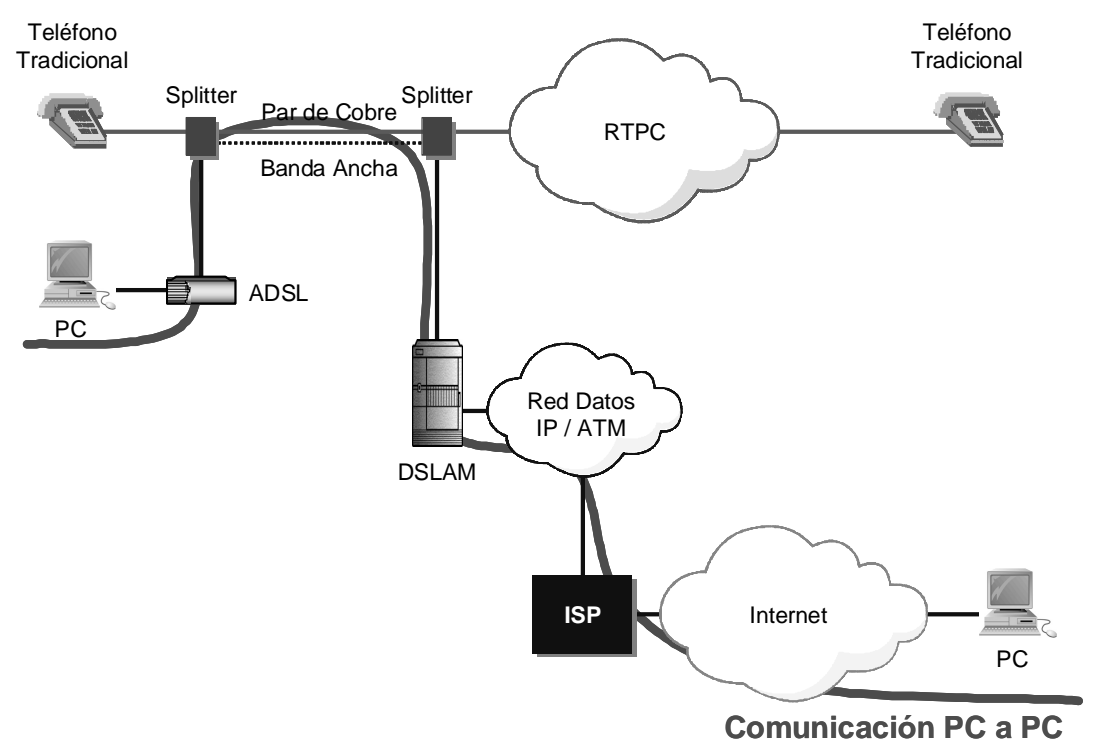


La provisión de telefonía IP sobre banda ancha. Los clientes conectados al servicio de banda ancha también podrían recibir telefonía IP sobre banda ancha. Para ello, una empresa tendría que conectarle al módem ADSL un adaptador telefónico (AT o IAD) que transforma las señales de voz en paquetes de datos y viceversa, tal como se muestra en la Figura $\mathrm{N}^{\circ} 3$. Este adaptador telefónico empaqueta la voz, y estos paquetes son transportados igual que un email o una comunicación a una página web, ingresan a la red del proveedor de banda ancha y se entregan en el servidor (o ISP) del proveedor de telefonía IP sobre banda ancha. Si la llamada es a un teléfono de la red fija tradicional, el proveedor de telefonía IP sobre banda ancha debe transformar los datos en señales de voz tradicional en protocolo TDM. Esto se hace con un media gateway, un equipo que hace de interface entre la red de datos y la red de telefonía local. Una vez transformadas las señales, el proveedor de telefonía IP los entrega a la telefónica tradicional en una telefonía local (PTR).

De esta manera, una empresa que invierte en adaptadores telefónicos y un servidor conectado a Internet puede ofrecer telefonía IP sobre banda ancha. Interconectado al servicio público telefónico puede proveer telecomunicaciones IP con los abonados a la red local aprovechando la infraestructura desplegada por el operador de la red de telefonía local y el proveedor de banda ancha.

FIGURA No $3: \quad$ VOZ SOBRE BANDA ANCHA

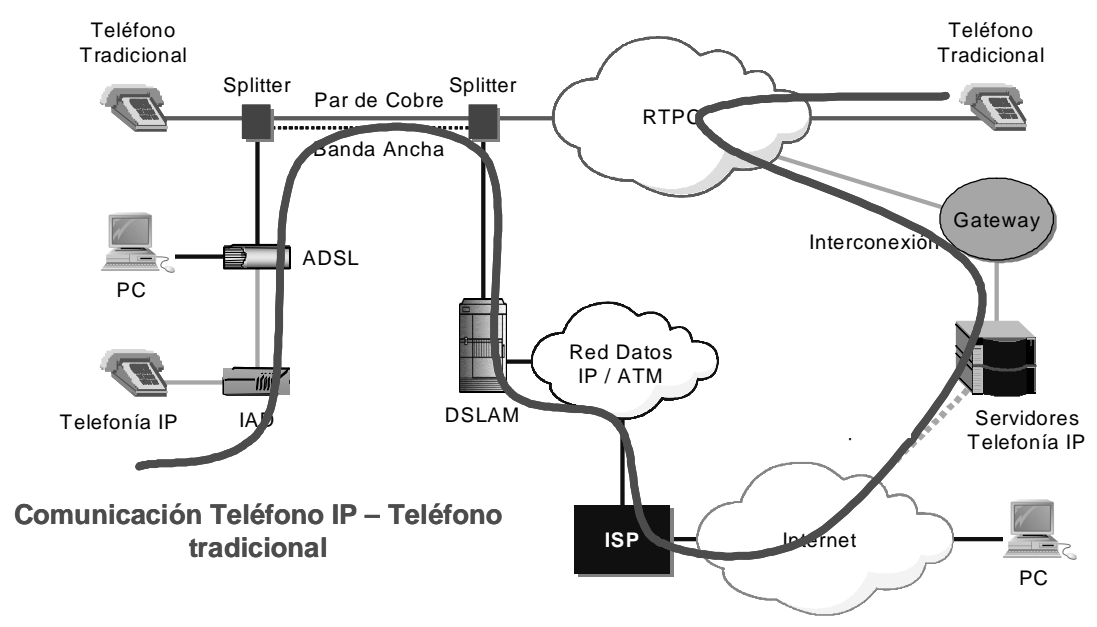


Otras tecnologías de telefonía IP. Para evitar confusiones es muy importante notar que la telefonía IP sobre banda ancha es sólo una de las maneras de proveer el servicio telefónico con una red de datos. Por eso, cuando se habla de telefonía IP, en realidad uno se está refiriendo a una familia de comunicaciones de voz que se proveen por medio de redes de datos. La diferencia fundamental entre la telefonía tradicional y la telefonía IP es que en esta última la voz se transporta en paquetes por una red de datos. Por el contrario, en una comunicación tradicional se abre un canal físico reservado para cada llamada.

La telefonía IP sobre banda ancha es uno de los integrantes de esa familia. Como se vio, en ese caso las conversaciones usan una conexión de banda ancha provista por un tercero que recibe el tráfico en su ISP. Existen a lo menos otros dos tipos de telefonía IP que utilizan redes de datos privadas para transportar conversaciones de voz.

El primer tipo es aquel que se les provee a empresas que, por otras razones, ya cuentan con una red privada interna de datos. Considérese, por ejemplo, el caso de un banco que contrata los servicios de una red privada de datos para interconectar sus sucursales y realizar operaciones entre ellas, tal como se muestra en la Figura $\mathrm{N}^{0} 4$. Esta red también se puede usar para conducir el tráfico de voz entre sucursales si los teléfonos de cada sucursal se conectan a equipos que concentran el tráfico (las unidades remotas o URA IP en la Figura $\mathrm{N}^{\circ} 4$ ). A estos equipos se les suma un soft switch, cuya función es etiquetar cada paquete de datos señalando su destino y su prioridad dentro de la red de datos.

Si la llamada es a otro teléfono dentro de la red privada de datos, los paquetes son transmitidos por la red hasta la unidad remota de destino y finalmente los recepciona el destinatario. Si, por el contrario, el destino de la llamada es a un teléfono conectado a la red de telefonía tradicional, el soft switch lo envía a un router interconectado a un media gateway, que transforma los paquetes de voz en una señal tradicional que se entrega en el punto de terminación de red (o PTR) de la compañía tradicional.

El segundo tipo de telefonía IP es aquel que reemplaza al protocolo TDM. En una red telefónica local, tal como la que se muestra esquemáticamente en la Figura $\mathrm{N}^{0}$ 1, se puede reemplazar total o parcialmente la tecnología tradicional para conmutar y transmitir por una tecnología IP. En este caso las unidades remotas digitalizan y empaquetan la señal de voz del suscriptor; la conmutación es reemplazada por un soft switch que identifica el destino de los datos de voz empaquetados; y la red de transmisión tradicional se reemplaza por una red de datos privada y cerrada con una arquitectura análoga a la que se muestra en la Figura $N^{\circ} 4$. Una diferencia entre esta telefonía y aquella provista por medio de banda ancha es que la red 


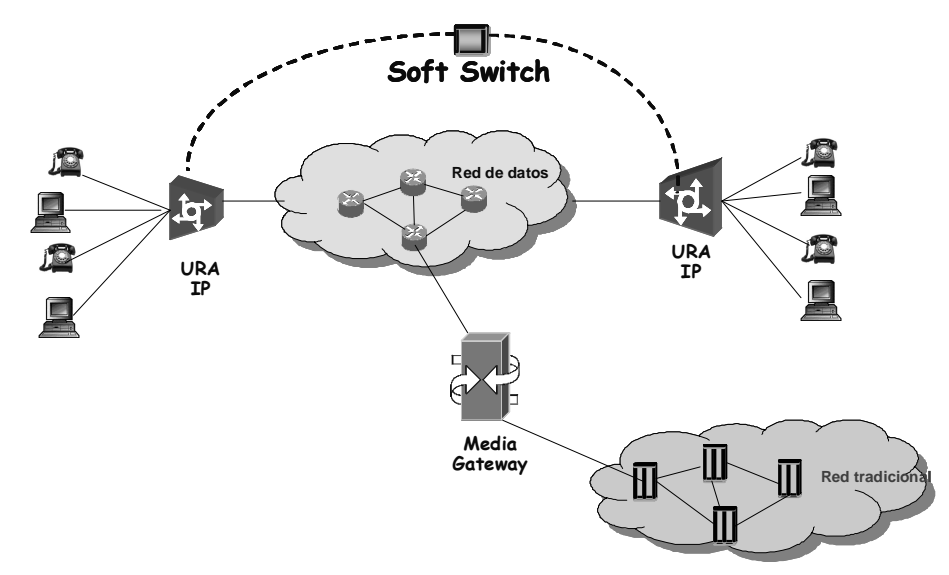

sigue siendo privada y, sobre todo, cerrada. Así, en este caso la tecnología IP sustituye a otra dentro de una red privada ${ }^{5}$. La voz sobre banda ancha es distinta, porque utiliza Internet.

Si bien la red tradicional de telefonía pública local se puede reemplazar por una red de datos y los así llamados soft switches IP, en los cálculos que presentamos líneas abajo suponemos que la conmutación y la transmisión siguen haciéndose con el protocolo tradicional TDM. Metodológicamente al menos, esto no implica pérdida de generalidad. Como se dijo en la introducción, el efecto de la telefonía IP sobre banda ancha es el mismo: la telefonía IP le saca tráfico a la red de telefonía local y ésta pierde economías de escala. Da lo mismo si la conmutación es tradicional o IP.

\section{El modelo}

\subsection{El mercado de la telefonía fija}

\subsubsection{La demanda por servicios de voz}

Suponemos un continuo de individuos de medida $S$, todos con la misma demanda por servicios de voz, $v=D^{v}\left(p^{v}\right)$, la que se muestra en las Figuras No 5 a y $5 b$.

${ }^{5}$ En realidad, se podría decir que se trata de progreso tecnológico dentro de la red tradicional, similar al que ha venido ocurriendo desde que las telefonistas fueron reemplazadas por conmutadores mecánicos, el cobre por fibra, etc. 
FIGURA N ${ }^{\circ}$ 5: $\quad$ LA DEMANDA POR TRÁFICO DE VOZ

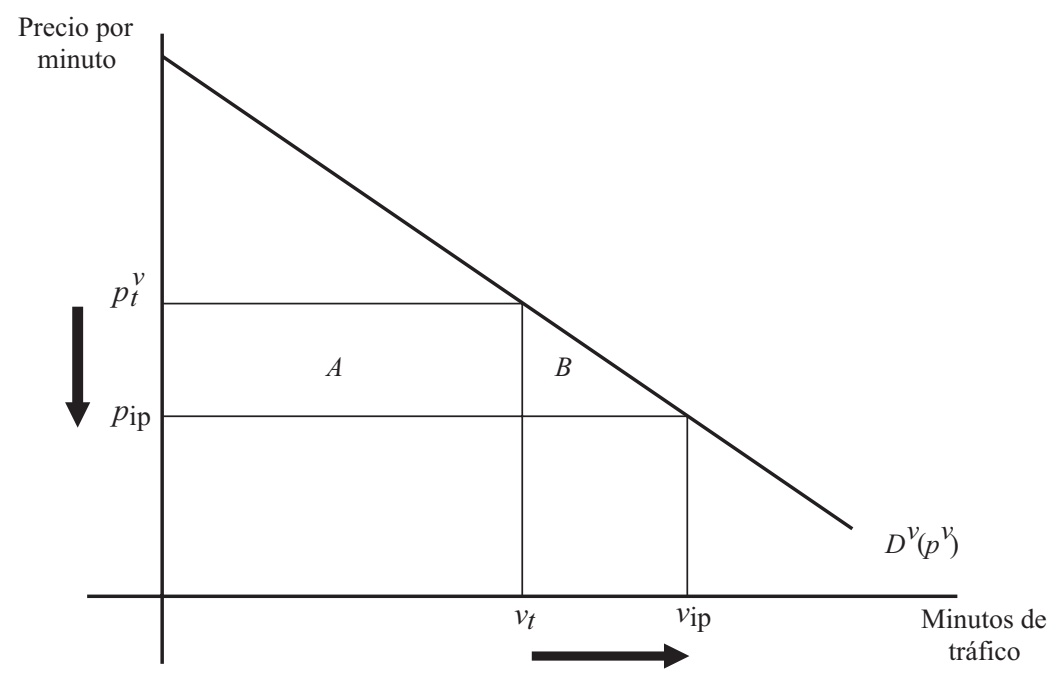

(a) Usuarios que emigran

hacia la voz sobre banda ancha

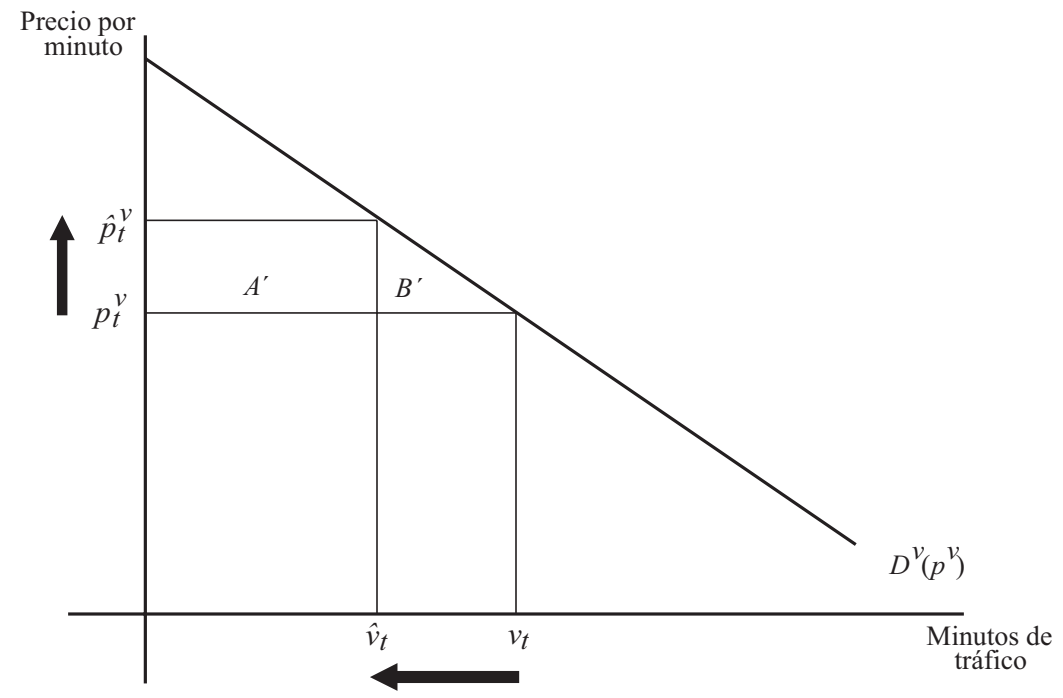

(b) Usuarios que permanecen

en la telefonía tradicional 


\subsubsection{Costos}

La red de acceso. El costo total de la red de acceso necesaria para conectar a $S$ abonados a la central es $C^{a}(S)$. Obviamente $\frac{d C^{a}}{d S}>0$ y, además, $\frac{d\left(C^{a} / S\right)}{d S}<0$ porque existen economías de densidad tales que el costo medio disminuye a medida que aumenta el número de clientes conectados a la red. Supondremos que esta función incluye los costos de mantención.

Conmutación y transmisión. La función de costos de conmutación y transmisión tiene tres partes ${ }^{6}$. La primera es función del tráfico total, $V_{t}$, donde $t$ denota voz tradicional. Suponemos que el costo total causado directamente por el tráfico es $C_{t}^{v}\left(V_{t}\right)$. Además existen costos que dependen del número de líneas activas, $C_{t}^{l}\left(L_{t}\right)$, donde $L_{t}$ es el número de líneas activas $^{7}$. Y, por último, costos fijos $F$, que no dependen ni del número de líneas activas a la red ni del tráfico (v. gr. los equipos de energía y clima, el housing necesario para albergar las centrales, la canalización de la fibra óptica).

En general, $L_{t} \leq S$. En efecto, cuando sólo existe telefonía fija tradicional, el único motivo para ser suscriptor es tener una línea activa, y en ese caso $L_{t}=S$. Por el contrario, cuando se introduce la telefonía IP sobre banda ancha habrá usuarios que, siendo suscriptores de la compañía de telefonía fija y usando sus pares de cobre, no tendrán una línea activa; en ese caso $L_{t}<S$.

Administración de una compañía telefónica fija. Suponemos que el costo de administrar una compañía telefónica de $S$ suscriptores es $A_{t}(S)$. Obviamente $\frac{d A_{t}}{d S}>0$.

Comentarios sobre la función de costos. El costo total de una empresa de telefonía fija con $S$ suscriptores, $L$ líneas activas y $V_{t}$ minutos de tráfico es

$$
C_{t}^{a}(S)+\left[C_{t}^{v}\left(V_{t}\right)+C_{t}^{l}\left(L_{t}\right)+F\right]+A_{t}(S)
$$

Nótese que los costos de una empresa de telefonía fija se pueden clasificar en cuatro categorías: aquellos que dependen del tráfico, $V_{t}$; aquellos que dependen del número de suscriptores, $S$; aquellos que dependen del número de líneas activas, $L_{t}$; y aquellos que son independientes de la escala, $F$.

\footnotetext{
${ }^{6}$ Véase Galetovic y Sanhueza (2006).

${ }^{7}$ Una línea activa es aquella por la que se hacen llamadas.
} 
Ahora bien, cuando se introduce la telefonía IP sobre banda ancha y un cierto número de usuarios desconecta su línea, disminuye el tráfico y el número de líneas activas, $L_{t}$ Por la forma de las funciones de costo, esto implica una disminución menos que proporcional del costo medio de conmutación y transmisión. Es decir, se pierden economías de escala.

Sin embargo, la pérdida de economías de escala se limita a los costos de la conmutación y la transmisión, porque el número de suscriptores de la compañía sigue siendo $S$. Éstos mantienen su par de cobre y siguen generando costos administrativos. Por lo tanto, la suma $C^{a}(S)+A_{t}(S)$ se sigue incurriendo y, desde el punto de vista de la evaluación social de la introducción de la telefonía IP sobre banda ancha, es irrelevante.

\subsubsection{Tarificación de la red fija}

El precio de los servicios de telefonía fija es una tarifa regulada en dos partes, $\left(p_{t}^{f}, p_{t}^{v}\right)$, donde $p_{t}^{f}$ es el cargo fijo, $p_{t}^{v}$ es el cargo por minuto.

Las tarifas se fijan para autofinanciar a la empresa eficiente. Si $L=S$, esto implica que

$$
S x\left[p_{t}^{f}+p_{t}^{v} \cdot D^{v}\left(p_{t}\right)\right]=C^{a}(S)+\left[C_{t}^{v}\left(V_{t}\right)+C_{t}^{l}\left(L_{t}\right)+F\right]+A_{t}(S)
$$

es la restricción de autofinanciamiento. Para simplificar, y por asemejarse a la práctica en Chile, supondremos en el resto de la sección teórica que la regulación de precios es tal que el cargo por conexión cubre exactamente el costo medio de la red de acceso y de los costos de administración, es decir

$$
p_{t}^{f}=\frac{C^{a}(S)+A_{t}(S)}{S}
$$

y que el cargo por minuto $p_{t}$ financia los costos asociados al tráfico más los costos fijos de la conmutación y transmisión, $F$, vale decir

$$
p_{t}^{v}=\frac{C_{t}^{v}\left(V_{t}\right)+C_{t}^{l}\left(L_{t}\right)+F}{V_{t}} .
$$

Con estas tarifas, el excedente neto de cada consumidor es

$$
\int_{p_{t}^{v}}^{\infty} D_{t}\left(p^{v}\right) d p^{v}-p_{t}^{f} .
$$




\subsection{El mercado de la banda ancha}

Sea $S_{b}=D_{b}\left(p_{b}\right)$ la demanda por banda ancha, donde $p_{b}$ es el cargo fijo por conectarse al servicio y $S_{b}$ el número de usuarios conectados al precio $p_{b}$. Supondremos, además, que si $p_{b}=0$ todos los abonados de la telefonía local se conectan a banda ancha, es decir $D_{b}(0)=S$, tal como se muestra en la Figura $\mathrm{N}^{\circ} 6$.

Suponemos que el servicio de banda ancha es ofrecido por una empresa distinta a la de telefonía local y que opera su propia red de datos. Para conectar a los suscriptores invierte en tecnología y la monta sobre el mismo par de cobre que la empresa de telefonía local utiliza para dar servicios de voz. Por el uso del par de cobre la empresa de banda ancha le paga a la empresa de telefonía local un precio regulado igual a $m$. Supondremos que este pago cubre exactamente los mayores costos en que incurre la empresa de telefonía local al compartir su red de acceso. Además, para simplificar suponemos que la banda ancha se produce con retornos constantes a escala y su función de costos es $c_{b} \cdot S_{b}$.

FIGURA N ${ }^{\circ}$ 6: $\quad$ EL MERCADO DE LA BANDA ANCHA

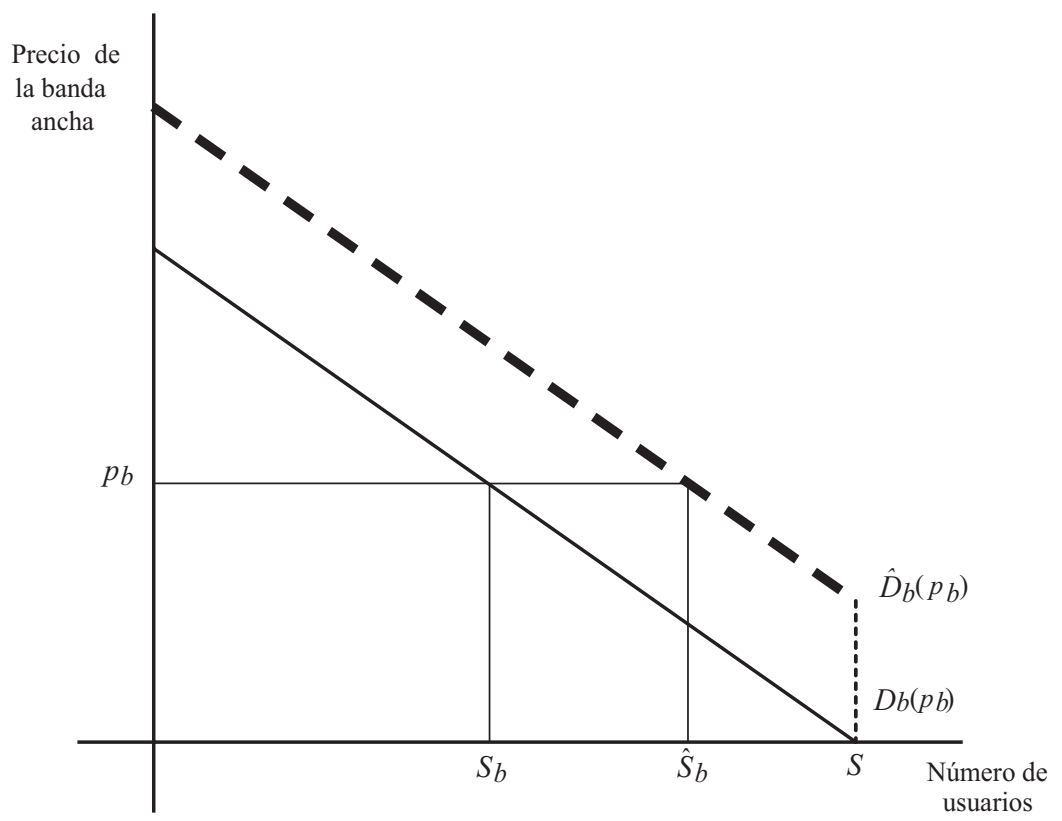


Suponiendo que el mercado de servicios de banda ancha es competitivo, el precio de la conexión a banda ancha es igual al costo medio de la red de datos desplegada por la empresa, más el cargo que le debe pagar a la empresa de telefonía local, es decir,

$$
p_{b}=m+c_{b}
$$

\subsection{Telefonía IP sobre banda ancha}

Las empresas de telefonía IP sobre banda ancha se montan sobre las redes de telefonía local y de datos. Por eso, deben invertir en electrónica y gastar en la gestión del negocio, mas no en la red de acceso.

El análisis que sigue supone que existe un continuo de proveedores idénticos de telefonía IP sobre banda ancha con curvas de costo en forma de $\mathrm{U}^{8}$. Además, el mercado de telefonía IP sobre banda ancha es perfectamente competitivo, por lo que la oferta de mercado es perfectamente elástica. Es sabido que en ese caso se puede modelar al mercado como una sola empresa.

Así, suponemos que el conjunto de las empresas de telefonía IP sobre banda ancha tiene costos de cursar tráfico $C_{\mathrm{ip}}^{v}\left(V_{\mathrm{ip}}\right)$ lineales en $V_{\mathrm{ip}}$; y en función de las líneas, $C_{\mathrm{ip}}^{l}\left(L_{\mathrm{ip}}\right)$, lineales en $L_{\mathrm{ip}}$. Además, los costos administrativos de manejar $L_{\mathrm{ip}}$ líneas son iguales a $A_{\mathrm{ip}}\left(L_{\mathrm{ip}}\right)$, lineales en $L_{\mathrm{ip}}$. Así, el costo total de la telefonía IP sobre banda ancha es

$$
C_{\text {ip }}^{\mathrm{v}}\left(V_{\text {ip }}\right)+C_{\text {ip }}^{l}\left(L_{\text {ip }}\right)+A_{\text {ip }}\left(L_{\text {ip }}\right) \text {. }
$$

Nótese que los retornos a escala constantes implican que si tráfico y suscriptores se duplican, también lo hacen los costos. Pero el costo medio por minuto o suscriptor depende de cuánto llame cada uno. Un suscriptor que llama el doble que otro genera el doble de costos sensibles al tráfico, pero los mismos costos de conmutación y transmisión. Por ende, el costo por minuto hablado es menor.

Por simplicidad en el análisis "teórico" que sigue supondremos que en equilibrio se cobra un precio único por minuto igual a

$$
p_{\text {ip }}=\frac{C_{\mathrm{ip}}^{\mathrm{v}}\left(V_{\mathrm{ip}}\right)+C_{\mathrm{ip}}^{l}\left(L_{\mathrm{ip}}\right)+A_{\mathrm{ip}}\left(L_{\mathrm{ip}}\right)}{V_{\mathrm{ip}}} .
$$

${ }^{8}$ Esto es, por supuesto, mutatis mutandis, dado que el costo total depende del número de líneas y tráfico. 


\section{Telefonía IP sobre banda ancha y bienestar}

Supuestos. Supondremos que quien emigra a telefonía IP sobre banda ancha sigue pagando el cargo fijo

$$
p_{t}^{f}=\frac{C^{a}(S)+A_{t}(S)}{S} .
$$

Se podría argumentar que esta es la manera “correcta” de tarificar. En efecto, quien emigre a la telefonía IP sobre banda ancha continuará usando la red de acceso y seguirá siendo cliente de la empresa de telefonía fija. Al mismo tiempo, el que emigre ya no llamará por la red fija. Por eso, supondremos que todo el costo de la conmutación y la transmisión lo pagan los usuarios que mantienen una línea activa. En el apéndice mostramos en qué cambia el análisis cuando la regulación le permite evitar parte o todo el cargo fijo a quienes emigran a la telefonía IP sobre banda ancha.

Segundo, supondremos que el precio de equilibrio por minuto de las llamadas IP es menor que el precio por minuto de las llamadas efectuadas por la red local, es decir $p_{\text {ip }}<p_{t}^{v}$. De lo contrario, es evidente que nadie se cambiaría a la telefonía IP sobre banda ancha.

Análisis. Nuestro análisis consiste en comparar el bienestar antes y después de la introducción de la telefonía IP sobre banda ancha. Antes de que esto ocurra el equilibrio de mercado es descrito por el vector de precios y cantidades

$$
\left(p_{t}^{f}, p_{t}^{v}, v_{t}, S ; p_{b}, S_{b} ; 0,0,0,0\right)
$$

donde los primeros cuatro componentes describen al mercado de la telefonía tradicional (cargo fijo, precio del minuto, minutos hablados por cada usuario y número de líneas activas); los siguientes dos al mercado de la banda ancha (precio y número de conexiones); y los últimos cuatro al mercado de la telefonía IP sobre banda ancha. Después de la introducción de la telefonía IP sobre banda ancha, el equilibrio es descrito por el vector

$$
\left(p_{t}^{f}, \hat{p}_{t}^{v}, \hat{v}_{t},\left(S-\hat{S}_{b}\right) ; p_{b}, S_{b} ; p_{t}^{f}, p_{\mathrm{ip}}, v_{\mathrm{ip}}, S_{b}\right),
$$

donde usamos el gorro para denotar que se trata del equilibrio después de que se introduce la telefonía IP sobre banda ancha. Nótese que los cuatro últimos componentes, que resumen a la telefonía IP sobre banda ancha, 
indican lo siguiente: el primer término, $p_{t}^{f}$, indica que los usuarios IP pagan el mismo cargo fijo que cuando eran suscriptores de la telefonía fija. También pagan un cargo por minuto $p_{\mathrm{ip}}$, generan un tráfico por línea igual a $v_{\mathrm{ip}}$. Por último, el número de líneas IP es igual a $\hat{S}_{b}$.

Ahora bien, porque $p_{\text {ip }}<p_{t}^{v}$, todo usuario conectado a la banda ancha emigrará hacia a la telefonía IP sobre banda ancha, llamará más $\left(v_{\mathrm{ip}}>v_{t}\right)$ y aumentará su bienestar en el equivalente al área $A+B$ en la Figura $\mathrm{N}^{\circ} 5 \mathrm{a}$. Ahora los minutos de tráfico son más baratos y, como el precio por minuto es menor, cada usuario llama más ${ }^{9}$.

Quienes ya tienen banda ancha se cambiarán a telefonía IP simplemente porque es más barata. Pero la introducción de la telefonía IP también aumenta la disposición a pagar por una conexión de banda ancha, en algo más que $A+B$. Ahora la alternativa es pagar $\hat{p}_{t}^{v}$ por las llamadas, y por eso la demanda por banda ancha aumenta, tal como se muestra en la Figura $\mathrm{N}^{\circ} 6$. Por eso, en equilibrio, el número de conexiones de banda ancha aumenta desde $S_{b}$ hasta $\hat{S}_{b}$.

El mayor bienestar neto de los $\hat{S}_{b}-S_{b}$ consumidores que se conectan a la banda ancha es igual al área

$$
\begin{aligned}
& (A+B) \times\left(\hat{S}_{b}-S_{b}\right)+\int_{S_{b}}^{\hat{S}_{b}} D_{b}^{-1}(\xi) d \xi-\left(m+c_{b}\right) \cdot\left(\hat{S}_{b}-S_{b}\right) \\
& \equiv(A+B) \times\left(\hat{S}_{b}-S_{b}\right)-\Delta^{1} .
\end{aligned}
$$

A este aumento se le suma el mayor bienestar que alcanzan los $S_{b}$ usuarios que ya estaban conectados a la banda ancha, y que alcanza a

$$
S_{b} \times(A+B)
$$

Sin embargo, no todos los suscriptores de la telefonía tradicional emigran hacia la telefonía IP sobre banda ancha. Como se puede ver en la Figura $N^{\circ} 6$, existen $S-\hat{S}_{b}$ clientes de la telefonía local que no se conectan a la banda ancha aun cuando sobre ella se pueden otorgar servicios de voz. Por lo tanto, el número de líneas activas caerá $S$ desde hasta $\hat{S}_{b}-S_{b}$. Para

${ }^{9}$ A pesar de que la calidad de la telefonía tradicional está regulada y es superior a la de la telefonía IP sobre banda ancha, por simplicidad, suponemos que la telefonía IP sobre banda ancha es un sustituto perfecto de la telefonía tradicional. Este supuesto sesga el resultado a favor de la introducción de la telefonía IP sobre banda ancha. 
asegurar el financiamiento de la red de telefonía tradicional con menos tráfico, el nuevo precio regulado por minuto es

$$
\hat{p}_{t}^{v}=\frac{C_{t}^{v}\left(\hat{V}_{t}\right)+C_{t}^{l}\left(S-\hat{S}_{b}\right)+F}{\hat{V}_{t}}
$$

con $\hat{V}_{t}=\left(S-\hat{S}_{b}\right) \times D^{v}\left(\hat{p}_{t}^{v}\right)$. El precio más alto por minuto reduce el bienestar de cada uno de los $S-\hat{S}_{b}$ clientes de la telefonía fija que no emigran a la telefonía IP sobre banda ancha en el área $A^{\prime}+B^{\prime}$ en la Figura $N^{\circ} 5 b$. La pérdida total de bienestar de estos consumidores es igual a

$$
\left(S_{b}-\hat{S}_{b}\right) \times\left(A^{\prime}+B^{\prime}\right)
$$

La migración de clientes hacia telefonía IP sobre banda ancha obliga a subir el precio de las llamadas en la red tradicional. De otra forma, la empresa no cumpliría con la restricción de autofinanciamiento (3.2). Podemos enunciar ahora el principal resultado de este trabajo:

Resultado 4.1. El cambio en bienestar debido a la introducción de la telefonía IP sobre banda ancha es igual a

$$
\hat{S}_{b} \times(A+B)-\Delta^{1}-\left(S-\hat{S}_{b}\right) \times\left(A^{\prime}+B^{\prime}\right) .
$$

Es claro que el efecto sobre el bienestar es ambiguo. Por un lado los consumidores que emigran hacia la telefonía IP sobre banda ancha aumentan su excedente. Pero el tráfico sobre la red de telefonía local cae, y esto obliga a aumentar las tarifas y les causa una pérdida neta de bienestar social a los usuarios que permanecen en la red de telefonía tradicional.

\section{Una estimación del cambio de bienestar}

En esta sección estimamos el orden de magnitud del cambio de bienestar que causaría la introducción de la telefonía IP sobre banda ancha.

\subsection{Preparando el modelo para los datos}

Demandas. Estimaciones recientes sugieren que la elasticidad-precio de la demanda por tráfico es baja y, para simplificar, la supondremos igual a 
cero $^{10}$. También supondremos fijo el número de usuarios y de conexiones de banda ancha, pero variaremos a discreción el número de usuarios que emigran hacia la telefonía IP sobre banda ancha ${ }^{11}$.

La evaluación social. Al suponer que el tráfico y los usuarios permanecen fijos, estamos reduciendo la pregunta a lo siguiente: ¿en cuánto cambia el costo total de servir a $S$ usuarios que llaman $V_{t}$ minutos si se introduce la telefonía IP sobre banda ancha? Si el costo total aumenta, la introducción hace caer el bienestar; si cae, el bienestar aumenta.

Ahora bien, nótese que el costo total de $\left(S, V_{t}\right)$ antes de la telefonía IP sobre banda ancha es, según nuestro modelo,

$$
C_{t}^{a}(S)+A_{t}(S)+\left[C_{t}^{v}\left(V_{t}\right)+C_{t}^{l}(S)+F\right]
$$

(esta es la expresión (3.1) que reproducimos por conveniencia). Al mismo tiempo, si a la telefonía IP sobre banda ancha emigran $L_{i p}$ usuarios, el costo social será

$$
C_{t}^{a}(S)+A_{t}(S)+\left[C_{t}^{v}\left(\hat{V}_{t}\right)+C_{t}^{l}\left(\hat{L}_{t}\right)+F\right]+\left[C_{\mathrm{ip}}^{v}\left(V_{\mathrm{ip}}\right)+C_{\mathrm{ip}}^{l}\left(L_{\mathrm{ip}}\right)\right]+A_{\mathrm{ip}}\left(L_{\mathrm{ip}}\right)
$$

con $\hat{L}_{t}+L_{\text {ip }}=S$ y $\hat{V}_{t}+V_{\text {ip }}=V_{t}$. El beneficio social neto de la introducción de la telefonía IP sobre banda ancha es, entonces,

$\left[C_{t}^{v}\left(V_{t}\right)+C_{t}^{l}(S)\right]-\left[C_{t}^{v}\left(\hat{V}_{t}\right)+C_{t}^{l}\left(\hat{L}_{t}\right)\right]-\left[C_{\mathrm{ip}}^{\mathrm{v}}\left(V_{\mathrm{ip}}\right)+C_{\mathrm{ip}}^{l}\left(L_{\mathrm{ip}}\right)+A_{\mathrm{ip}}\left(L_{\mathrm{ip}}\right)\right]$

De esta diferencia es evidente el siguiente resultado:

${ }^{10}$ El estudio tarifario elaborado por Telefónica CTC S.A. en 2004 suponía que la elasticidad precio del servicio local medido, que representa casi un $65 \%$ del tráfico iniciado en la red fija, era de $-0,0878$ en horario normal y $-0,2889$ en horario reducido. La elasticidad precio de las llamadas a teléfonos móviles era de $-0,4913$ y $-0,4$ en horario normal y reducido respectivamente. La elasticidad precio de las llamadas de larga distancia nacional de $-0,7627$ en horario normal y de $-0,5176$ en horario reducido. Considerando la participación de cada uno de estos tráficos, la elasticidad precio promedio era de aproximadamente $-0,3115$.

${ }^{11} \mathrm{Al}$ suponer que la demanda por tráfico y por conexiones a banda ancha son perfectamente inelásticas estamos omitiendo parte de los beneficios de introducir telefonía IP sobre banda ancha. Sin embargo, tampoco estamos considerando que el aumento de precio de la telefonía tradicional reduce el bienestar de quienes permanecen en la telefonía tradicional. En todo caso, líneas abajo explicamos que tales efectos son de segundo orden. 
Resultado 5.1. Desde el punto de vista de la evaluación social, $C_{t}^{a}(S)+A(S)$ es irrelevante.

La introducción de la telefonía IP sobre banda ancha no cambia el tamaño de la red de acceso. Tampoco debiera alterar mucho los costos administrativos de la empresa que la provee — después de todo, los clientes tienen que seguir siendo atendidos y facturados aunque su línea no esté activa-. Por eso:

Resultado 5.2. Los méritos relativos de la telefonía IP sobre banda ancha dependen, fundamentalmente, de las diferencias de costos en conmutación y transmisión.

Por un lado, tal como se aprecia en la expresión (5.1), la caída de tráfico y líneas reduce los costos de la empresa de telefonía tradicional. Por el otro, ahora se deben incurrir en nuevos costos para proveer la telefonía IP sobre banda ancha.

Los efectos distributivos de la telefonía IP sobre banda ancha. La eXpresión (5.1) enfoca el problema desde el lado de los costos. Y así debe ser, si se trata de averiguar el beneficio social neto de la introducción de la telefonía IP sobre banda ancha. Pero, al mismo tiempo, nos interesan los efectos distributivos. Por la manera que se tarifica la telefonía fija en Chile, la introducción de la telefonía IP sobre banda ancha debiera aumentar las tarifas de la telefonía tradicional, para continuar autofinanciando a la empresa eficiente. Así, también nos interesa conocer, por un lado, en cuánto aumenta la cuenta de los que se quedan en la red fija; y, por el otro lado, cuánto ganan quienes se van a la telefonía IP sobre banda ancha.

Acceso. Una parte del efecto distributivo dependerá de cuánto deberán continuar pagando a la empresa de telefonía fija quienes emigren a la telefonía IP sobre banda ancha. Aquí supondremos que quienes emigran seguirán pagando todos los costos medios de la red de acceso y de administración de la empresa de telefonía fija, es decir

$$
p_{t}^{f}=\frac{C^{a}(S)+A_{t}(S)}{S} .
$$

La lógica de este supuesto es que esos servicios siguen siendo usados por estos suscriptores. Al mismo tiempo, nos parece coherente con la forma en que se han regulado las tarifas en Chile. 
El efecto distributivo. Una vez hecho este supuesto, el efecto distributivo se puede computar con un par de cálculos simples. Sea $\operatorname{IMe}_{t}(S, S)$ el ingreso medio por línea cuando la compañía tiene $S$ líneas activas. Por la forma en que se calculan las tarifas, siempre se cumple que

$$
S \cdot \mathrm{IMe}_{t}(S, S)=C_{t}^{a}(S)+A_{t}(S)+\left[C_{t}^{v}\left(V_{t}\right)+C_{t}^{l}(S)+F\right] \equiv S \cdot \mathrm{CMe}_{t}(S, S),
$$

donde $\mathrm{CMe}_{t}(S, S)$ es el costo medio por línea. Vale decir, los ingresos por línea son suficientes para cubrir el costo de la empresa eficiente. Este ingreso por línea promedio se puede descomponer en

$$
\begin{aligned}
S \cdot \operatorname{IMe}_{t}(S, S) & \equiv \hat{L}_{t} \cdot \operatorname{IMe}_{t}\left(\hat{L}_{t}, S\right)+L_{\text {ip }} \cdot \operatorname{IMe}_{t}\left(L_{\mathrm{ip}}, S\right) \\
& \equiv \hat{L}_{t} \cdot \mathrm{CMe}_{t}\left(\hat{L}_{t}, S\right)+L_{\mathrm{ip}} \cdot \mathrm{CMe}_{t}\left(L_{\mathrm{ip}}, S\right) \equiv S \cdot \mathrm{CMe}_{t}(S, S) .
\end{aligned}
$$

$\operatorname{IMe}_{t}\left(\hat{L}_{t}, S\right)$ es el ingreso medio por línea de los clientes que no emigran a la telefonía IP sobre banda ancha, pero cuando aún no se introduce la telefonía IP sobre banda ancha; $\operatorname{IMe}_{t}\left(L_{\mathrm{ip}}, S\right)$ es el ingreso medio por línea de los clientes que emigran a la telefonía IP sobre banda ancha, pero antes de la telefonía IP sobre banda ancha. Y de manera similar para los costos medios por línea. Una vez introducida la telefonía IP sobre banda ancha, los costos e ingresos medios cambian a

$$
\operatorname{IMe}_{t}\left(\hat{L}_{t}, \hat{L}_{t}\right)=\mathrm{CMe}_{t}\left(\hat{L}_{t}, \hat{L}_{t}\right)
$$

que es la igualdad de ingresos y costos que la ley le otorga a la empresa regulada; y

$$
\operatorname{IMe}_{\text {ip }}\left(L_{\text {ip }}, L_{\text {ip }}\right)=\mathrm{CMe}_{\text {ip }}\left(L_{\text {ip }}, L_{\text {ip }}\right)
$$

que es una forma de escribir la condición de equilibrio del mercado de la telefonía IP sobre banda ancha. La primera expresión dice que el ingreso medio generado por los clientes de la telefónica tradicional una vez que sólo quedan $\hat{L}_{t}$ líneas activas debe igualarse con el costo medio por línea. Y de manera similar para la telefonía IP sobre banda ancha. El efecto distributivo de la telefonía IP sobre banda ancha es, entonces,

$$
\begin{aligned}
& \hat{L}_{t} \cdot\left[\operatorname{IMe}_{t}\left(\hat{L}_{t}, S\right)-\operatorname{IMe}_{t}\left(\hat{L}_{t}, \hat{L}_{t}\right)\right] \\
& \text { у } \\
& L_{\text {ip }} \cdot\left[\operatorname{IMe}_{\text {ip }}\left(L_{\text {ip }}, L_{\text {ip }}\right)-\operatorname{IMe}_{t}\left(L_{\text {ip }}, S\right)\right] .
\end{aligned}
$$


Las expresiones (5.3) y (5.4) permiten calcular el efecto distributivo y éstas serán reportadas más abajo.

Una descomposición alternativa. La descomposición (5.2) se puede ocupar para separar las fuentes del efecto distributivo. Nótese que

$-\hat{L}_{t} \cdot\left[\operatorname{IMe}_{t}\left(\hat{L}_{t}, S\right)-\mathrm{CMe}_{t}\left(\hat{L}_{t}, S\right)\right]=L_{\text {ip }} \cdot\left[\operatorname{IMe}_{t}\left(L_{\text {ip }}, S\right)-\mathrm{CMe}_{t}\left(L_{\text {ip }}, S\right)\right] \equiv Z$

En la práctica ocurre que $Z<0$, porque la estructura tarifaria actual está calculada para que parte de los costos que no varían con el tráfico se cobren en el cargo variable por minuto. Los clientes que emigrarían a IP son los de tráfico más alto que generan ingresos mayores que los costos medios de servirlos. Así,

$$
\begin{aligned}
& \operatorname{IMe}_{t}\left(\hat{L}_{t}, S\right)=\mathrm{CMe}_{t}\left(\hat{L}_{t}, S\right)-\frac{Z}{\hat{L}_{t}} \\
& \mathrm{y} \\
& \operatorname{IMe}_{t}\left(L_{\mathrm{ip}}, S\right)=\mathrm{CMe}_{t}\left(L_{i p}, S\right)-\frac{Z}{L_{\text {ip }}} .
\end{aligned}
$$

De esta forma, cada usuario que permanece en la telefonía fija cuando se introduce la telefonía IP sobre banda ancha debe generar más ingresos iguales a

$$
\operatorname{IMe}_{t}\left(\hat{L}_{t}, S\right)-\operatorname{IMe}_{t}\left(\hat{L}_{t}, \hat{L}_{t}\right)=\left[\mathrm{CMe}_{t}\left(\hat{L}_{t}, \hat{L}_{t}\right)-\mathrm{CMe}_{t}\left(\hat{L}_{t}, S\right)\right]-\frac{Z}{\hat{L}_{t}}
$$

El primer término del lado derecho corresponde al aumento de costos medios debido a la caída del número de usuarios. El segundo término, al hecho que los usuarios que emigran a la telefonía IP sobre banda ancha ya no pagan más que el costo medio de darles el servicio de telefonía tradicional.

De manera similar, cada usuario que emigra a la telefonía IP sobre banda ancha genera menores ingresos iguales a

$$
\operatorname{IMe}_{t}\left(L_{\mathrm{ip}}, S\right)-\mathrm{IMe}_{\mathrm{ip}}\left(L_{\mathrm{ip}}, L_{\mathrm{ip}}\right)=\left[\mathrm{CMe}_{t}\left(L_{\mathrm{ip}}, S\right)-\mathrm{CMe}_{\mathrm{ip}}\left(L_{\mathrm{ip}}, L_{\mathrm{ip}}\right)\right]-\frac{Z}{L_{\mathrm{ip}}}
$$


Vale decir, parte del beneficio que obtiene se debe a los menores costos medios de la IP. Pero también gana porque ya no contribuye a financiar los costos no sensibles al tráfico de la red fija, tal como lo tiene pensado la tarificación de la telefonía fija regulada actualmente vigente en Chile. Líneas abajo cuantificaremos cada una de estas expresiones.

\subsection{Datos}

Tráfico y acceso a banda ancha. En nuestras estimaciones utilizaremos el número de líneas y tráfico supuestos en el estudio tarifario de la última fijación de tarifas de Telefónica CTC. Este estudio modeló una empresa eficiente para atender a 2.982.555 líneas, por las que transitan 2.062,17 millones de minutos al mes, o 691 minutos por línea (véase la parte inferior del Cuadro $\mathrm{N}^{\circ} 1$ ). Es importante notar que este tráfico incluye a todo el tráfico local de voz e Internet conmutado; a todas las salidas de tráfico, hacia carriers de larga distancia, teléfonos móviles, servicios complementarios; y a todas las entradas de tráfico que provienen de otras redes.

CUADRO N ${ }^{\circ}$ 1: $\quad$ COMPOSICIÓN DE TRÁFICO

SUBTEL Y ESTUDIO TARIFARIO

(1)

Subtel (2004b)

Estudio tarifario

Tráfico

(en millones de minutos)

Fijo a fijo

Fijo a móvil

Móvil a fijo

Servicios complementarios

LDI (entrada)

LDI (salida)

LD nacional

Internet

Total minutos

Líneas

Tráfico por línea

(en minutos)

$\begin{array}{cccc}982,05 & 48,09 \% & 991,71 & 48,09 \% \\ 122,03 & 5,98 \% & 123,23 & 5,98 \% \\ 126,83 & 6,21 \% & 128,08 & 6,21 \% \\ 50,87 & 2,49 \% & 51,37 & 2,49 \% \\ 45,82 & 2,24 \% & 46,27 & 2,24 \% \\ 20,14 & 0,99 \% & 20,34 & 0,99 \% \\ 155,01 & 7,59 \% & 156,53 & 7,59 \% \\ 539,34 & 26,41 \% & 544,64 & 26,41 \% \\ 2042,09 & 100 \% & 2062,17 & 100 \% \\ 3.260 .444 & & & \\ 626 & & 2.982 .555 & \\ & & 691 & \end{array}$

Nota: Para descomponer el tráfico total supuesto en el estudio tarifario, se utilizaron las prorratas que se desprenden de la información reportada por Subtel y expuestas en la columna 1.

Fuente: Columna 1, Subtel (2004b). La fuente del tráfico total y del número de líneas supuestas en el estudio tarifario es Telefónica CTC. 
También notamos que parte de los costos e ingresos de una compañía de telefonía fija proviene de las entradas de tráfico. Estos cargos de acceso no son pagados por los clientes de la empresa de telefonía fija, sino por los que ingresan llamada a la red. Sin embargo, por definición, todo tráfico de entrada se le puede asignar a una línea. De ahí que trabajaremos con tráfico total por línea de la telefónica tradicional. En algún sentido, cada línea se puede entender como un paquete de tráfico.

Los números del estudio tarifario corresponden a una proyección promedio de líneas y tráficos durante cinco años. Es útil, por tanto, contrastarlos con datos más recientes de líneas y tráfico efectivo de todo el mercado nacional. De acuerdo con Subtel (2004b), a junio de 2004 existían 3.260.444 líneas telefónicas tradicionales en el país, mientras que el número de conexiones de banda ancha alcanzaba a 424.016 (equivalentes al 13\% de las líneas). El tráfico total generado y atraído por líneas fijas fue 2.042,09 millones de minutos durante junio de 2004, el desglose lo presentamos en el Cuadro $N^{\circ} 1$. Así, el tráfico promedio por línea alcanzó a 626 minutos mensuales.

Migración desde telefonía tradicional hacia IP. Si la telefonía IP sobre banda ancha fuese un sustituto perfecto de la fija y los costos de cambio fueran insignificantes, todos los usuarios conectados a la banda ancha emigrarían, aun si la telefonía IP sobre banda ancha fuera apenas algo más barata. En la práctica, sin embargo, hay costos de cambio, y es incierto cuántos usuarios emigrarán hacia la telefonía IP sobre banda ancha. Por eso estimamos tres escenarios en que el tráfico total (de entrada y salida) cae $5 \%, 15 \%$ y $25 \%$.

Por supuesto, por algunas líneas pasa mucho más tráfico que por otras. Para elegir las líneas que emigran hacia la telefonía IP sobre banda ancha supondremos, en cada caso, lo siguiente:

Supuesto 1. Sólo emigran a la telefonía IP sobre banda ancha usuarios con tráfico local de salida menor que 3.000 minutos al mes.

Esto lo suponemos porque prácticamente todos los clientes con más de 3.000 minutos de tráfico local de salida son comerciales y a esos niveles de tráfico se justifica contratar directamente con una telefónica. Puesto de otra forma, un cliente con ese tráfico no compraría una conexión ADSL para trasladarse a la telefonía IP sobre banda ancha, sino que negociaría directamente. 
Supuesto 2. Entre los usuarios con tráfico local de salida menor que 3.000 minutos al mes emigran a la voz sobre banda ancha quienes llaman más.

Es decir, cuando suponemos que el tráfico cae 5\%, también suponemos que emigran a la telefonía IP sobre banda ancha aquellos clientes de más tráfico entre aquellos con tráfico local de salida menor que 3.000 minutos al mes ${ }^{12}$. Tal como se aprecia en el Cuadro $\mathrm{N}^{\circ} 2$, columna 2, fila Clientes que emigran, éstos son 33.718 usuarios. Cuando emigra el 15\% del tráfico, suponemos que son 149.683 (Cuadro $\mathrm{N}^{\circ}$ 2, columna 3, fila Clientes que emigran). Y así sucesivamente.

Antes de seguir es conveniente notar que tanto el Supuesto 1 como el Supuesto 2 pueden parecer exagerados. Primero, es posible que a un comercio o industria le convenga contratar directamente con una telefónica antes de alcanzar 3.000 minutos de tráfico de salida. Segundo, es perfectamente posible que usuarios con tráfico más bajo tengan banda ancha ${ }^{13}$. Sin embargo, ambos son convenientes porque sesgan los resultados en favor de la voz sobre banda ancha. En efecto, al suponer que emigran clientes con tráfico alto estamos minimizando el número de usuarios necesarios para sumar determinado porcentaje de tráfico. De esta forma, la pérdida de economías de escala de la telefonía tradicional es la menor posible.

Sea como fuere, la relación entre tráfico y clientes se obtuvo de la así llamada curva de duración de llamadas de clientes de CTC de mayo de 2004. Con estos datos confeccionamos una Curva de Lorenz, que mostramos en la Figura $\mathrm{N}^{\circ}$ 7. Cada punto de la Curva de Lorenz indica el porcentaje del tráfico que acumula el respectivo porcentaje de líneas, ordenadas desde aquellas que llaman menos hasta aquellas que llaman más. En un extremo están aquellas líneas que no registran tráfico, 575.987 ó 19,3\% del total ${ }^{14}$. Al

${ }^{12}$ El lector atento notará en la columna 2 del Cuadro $\mathrm{N}^{\circ} 2$ que el tráfico de los clientes que migran es, en promedio, 3.062 minutos al mes. Este número supera los 3.000 minutos del supuesto 1 porque, además del tráfico local de salida, incluye todos los restantes minutos generados por una línea por tráfico de salida distinto del local y de entrada.

${ }^{13}$ Un árbitro anónimo sugiere un ejemplo: un matrimonio de profesionales sin hijos tal que ambos trabajan. Hablan poco, pero con seguridad contratan banda ancha.

${ }^{14}$ Estas líneas incluyen a las desconectadas por no pago, pero también a las de grandes clientes comerciales (v.gr. un banco) asociadas a un así llamado número pagador. Un número pagador de un gran cliente es aquel al cual se le facturan todas las llamadas hechas por los teléfonos directos del cliente. Como contrapartida de los números pagadores están los demás números asociados a éste, que, consecuentemente, registran un tráfico mensual igual a cero; lo que explica en parte las 424.520 líneas sin tráfico. 
CUADRO N 2: $\quad$ ESTADÍSTICAS BÁSICAS DE LÍNEAS Y TRÁFICO

\begin{tabular}{|c|c|c|c|c|}
\hline Clientes / tráfico $\rightarrow$ & $\begin{array}{c}(1) \\
100 / 100\end{array}$ & $\begin{array}{c}(2) \\
99 / 95\end{array}$ & $\begin{array}{c}(3) \\
97 / 85\end{array}$ & $\begin{array}{c}(4) \\
93 / 75\end{array}$ \\
\hline \multicolumn{5}{|l|}{ Número de líneas ${ }^{1}$} \\
\hline Clientes que permanecen ${ }^{2}$ & & 2.949.137 & 2.833 .172 & 2.661 .831 \\
\hline Bajo tráfico & & 2.933.307 & 2.817 .343 & 2.646 .002 \\
\hline Alto tráfico & & 15.830 & 15.830 & 15.830 \\
\hline Clientes que migran ${ }^{5}$ & & 33.718 & 149.683 & 321.024 \\
\hline Todos los clientes 6 & 2.982 .855 & 2.982 .855 & 2.982 .855 & 2.982 .855 \\
\hline \multicolumn{5}{|l|}{$\begin{array}{l}\text { Tráfico mensual } \\
\text { (millones de minutos) }\end{array}$} \\
\hline Clientes que permanecen & & $1.958,94$ & $1.751,04$ & $1.546,70$ \\
\hline Bajo tráfico & & $1.691,89$ & $1.484,00$ & $1.279,66$ \\
\hline Alto tráfico & & 267,05 & 267,05 & 267,05 \\
\hline Clientes que migran & & 103,23 & 311,13 & 515,47 \\
\hline Todos los clientes & $2.062,17$ & $2.062,17$ & $2.062,17$ & $2.062,17$ \\
\hline \multicolumn{5}{|l|}{$\begin{array}{l}\text { Tráfico promedio } \\
\text { (minutos) }\end{array}$} \\
\hline Clientes que permanecen & & 664 & 618 & 581 \\
\hline Bajo tráfico & & 577 & 527 & 484 \\
\hline Alto tráfico & & 16.870 & 16.870 & 16.870 \\
\hline Clientes que migran & & $3.062^{8}$ & 2.079 & 1.606 \\
\hline Todos los clientes & 691 & 691 & 691 & 691 \\
\hline
\end{tabular}

Notas: (1) El número total de líneas (2,98 millones) es el supuesto en el estudio tarifario de Telefónica CTC, en 2004. (2) Los clientes que permanecen son aquellos que no se cambian a voz sobre banda ancha. (3) Los clientes de bajo tráfico son todas aquellas líneas que en cada caso llaman menos. Éstas incluyen a 575.987 líneas que no generan tráfico. (4) Los clientes de alto tráfico son aquellos que originan más de 3.000 minutos de llamadas locales mensuales. (5) En cada caso se supuso que migran hacia la telefonía IP sobre banda ancha aquellos usuarios que llaman más, pero que no son de alto tráfico. Por lo tanto, entre los clientes que migran sólo hay líneas con a lo más 3.000 minutos mensuales de tráfico local de salida. Los clientes de alto tráfico son comerciales y no contratarán una conexión de banda ancha para llamar por teléfono. (6) La distribución del tráfico se obtuvo de las estadísticas de llamados de 2,20 millones de líneas en mayo de 2004. El número de líneas en cada categoría se escaló para que sumaran los 2,98 millones supuestos en el estudio tarifario. (7) El tráfico incluye llamadas locales intrared, llamadas locales a otras redes, llamadas de larga distancia nacional (entrada y salida) y llamadas entre líneas fijas y teléfonos móviles (entrada y salida) y tráfico de Internet conmutado. En todos los casos se supone que el tráfico de Internet conmutado permanece en la red tradicional y no migra hacia la red IP. (8) El número de minutos supera los 3.000 porque se incluye no sólo el tráfico de salida sino también el tráfico de entrada generado por cada número.

Fuente de los datos: Telefónica CTC. Cálculos de los autores. 


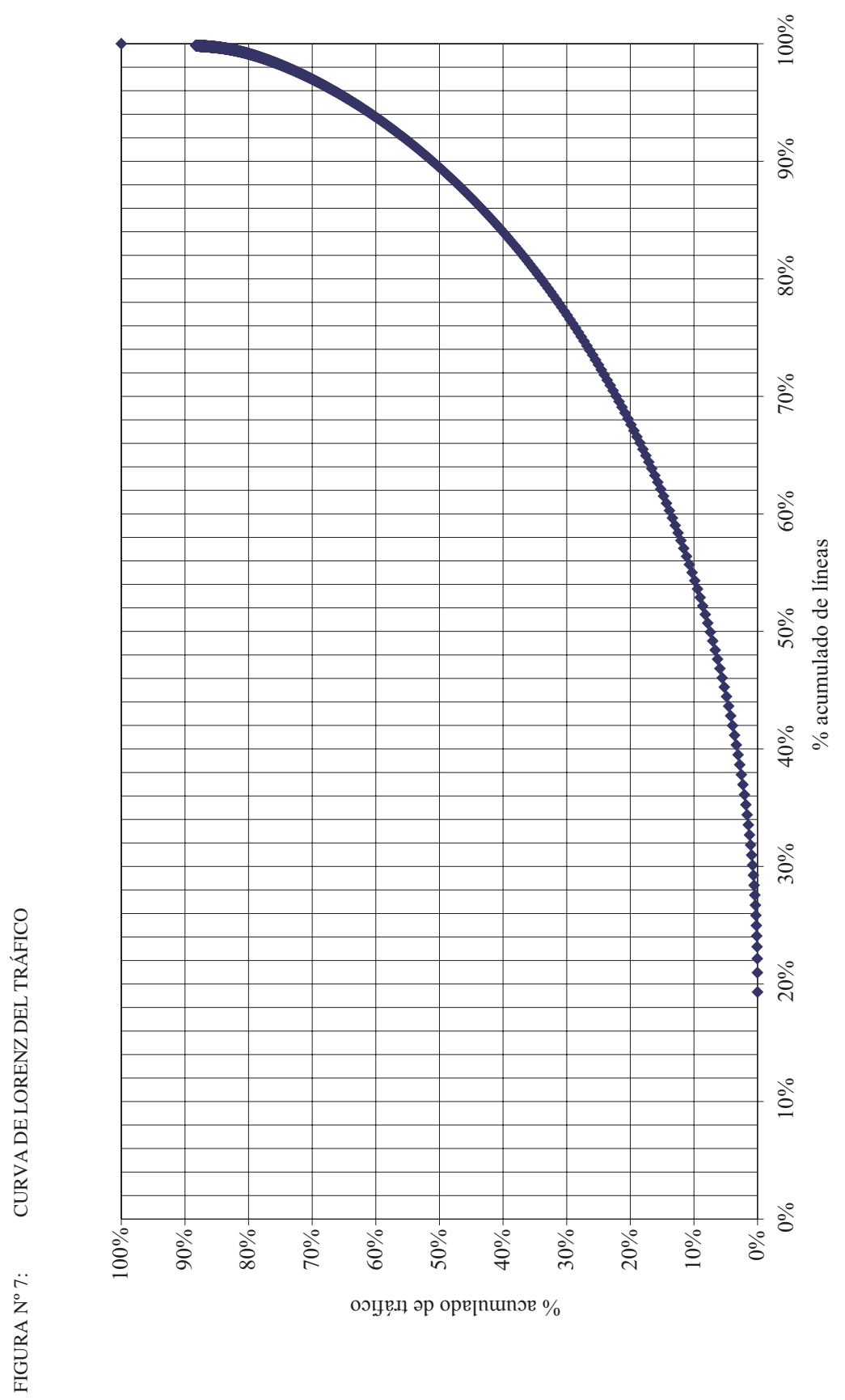


otro extremo están las 15.830 líneas que llaman más de 3.000 minutos (señalados como clientes de alto tráfico en el Cuadro $\mathrm{N}^{\circ} 2$ ), apenas el $0,78 \%$ de las líneas pero que originan el 17,6\% del tráfico (esto se aprecia en la Figura $\mathrm{N}^{\circ} 7$ con el salto de la Curva de Lorenz al llegar a 100\%). Entre esas dos están los potenciales emigrantes hacia la telefonía IP sobre banda ancha.

Las columnas 2 a 5 del Cuadro $\mathrm{N}^{\circ} 2$ muestran las estadísticas básicas de quienes emigran y permanecen en cada uno de los cuatro escenarios considerados. En cada caso se muestra el número de líneas que emigra.

Es importante notar que el número de líneas que originó la curva de duración (2.197.905) es menor que el usado en el estudio tarifario $(2.982 .855)^{15}$. Para llegar de uno a otro, se escaló proporcionalmente cada categoría de clientes con el factor

$$
1,367 \approx \frac{2.982 .855 \text { líneas }}{2.197 .905 \text { líneas }} .
$$

De manera similar, la curva de duración reporta sólo el tráfico de salida local (intrared) Sin embargo, como ya se dijo, una buena parte del tráfico que circula por la red es hacia otras redes o de larga distancia; o bien entra desde otras redes o de llamadas de larga distancia. Por eso, necesitamos sumarle a cada usuario el tráfico adicional que su línea genera o atrae. Para hacerlo, multiplicamos los tráficos de cada categoría por el factor

$$
1,495 \approx \frac{509 \text { minutos }}{340 \text { minutos }},
$$

la razón entre tráfico medio total por línea y el tráfico medio de salida local por línea. El resultado son los montos ajustados que se reportan en el Cuadro $\mathrm{N}^{\circ} 2$.

Nótese que en el Cuadro $\mathrm{N}^{\circ} 1$ se reporta un tráfico medio total por línea de 691 minutos, mientras que para calcular el factor (5.5) se utilizaron sólo 509 minutos. La diferencia se debe a que supondremos que el tráfico de Internet conmutado, que representa el 26,21\% del tráfico total, nunca emigra a telefonía IP sobre banda ancha. Por lo mismo, es importante notar que

\footnotetext{
${ }^{15}$ Esto ocurre en buena parte porque el estudio tarifario cubre cinco años (entre 2004 y 2009) y supone que el tráfico crece.
} 
para que emigre, por ejemplo, el 5\% del tráfico total a la red IP, es necesario extraerle el

$$
\frac{5 \%}{1-0,2621} \approx 6,78 \%
$$

del tráfico distinto al de Internet conmutado.

Costos e ingresos de la telefonía tradicional. Los costos de la telefonía tradicional que usamos en este estudio provienen del modelo desarrollado por Telefónica CTC, y que la Subtel usó (luego de pasar por la comisión de peritos) para fijar las tarifas finales de Telefónica CTC. Como se dijo, este modelo es el de una empresa eficiente diseñada para atender la demanda señalada más arriba cuyo costo de capital anual es 9,74\%.

El modelo es detallado. Por un lado, permite separar los costos debidos a la red de acceso, al resto de la red (conmutación y transmisión) y a la administración de la empresa. Por otro lado, separa los costos que son sensibles al tráfico de los que no lo son. Telefónica CTC nos entregó los resultados del modelo para cada uno de los casos bajo análisis en planillas desagregadas, que luego nosotros sumamos para obtener los resultados que reportamos.

La parte superior del Cuadro $\mathrm{N}^{\circ} 3$ (Telefonía tradicional; costos medios) muestra el costo por línea cuando el tráfico se cursa por una red de telefonía tradicional. La columna 1 (100/100) reporta los promedios para todas las líneas cuando no hay telefonía IP sobre banda ancha y todo el tráfico se cursa por la red de telefonía fija. En ese caso el costo medio de la red de acceso es \$3.065 por línea; el de los componentes que no varían con el tráfico de la conmutación y transmisión es \$2.759 por línea; y el costo medio administrativo es $\$ 4.087$ por línea. Por último, los costos que varían con el tráfico se estiman en \$3,14 por minuto.

Las columnas siguientes (2 a 5) reportan los costos medios por línea cuando parte de los usuarios emigra a la telefonía IP sobre banda ancha y, por tanto, caen el tráfico y el número de líneas activas. Nótese que ni los costos de acceso ni los administrativos varían. Esto obedece a que los usuarios de la telefonía IP sobre banda ancha siguen usando la red de acceso y siendo suscriptores de la empresa de telefonía tradicional. Por el contrario, los costos por línea de la conmutación/transmisión y el costo por minuto del tráfico aumentan y crecen a medida que disminuye el tráfico y el número de líneas activas. Esto refleja la pérdida de economías de escala. 
CUADRO No $3: \quad$ COSTOS E INGRESOS

\begin{tabular}{lcccc}
\hline Clientes / tráfico $\rightarrow$ & $(1)$ & $(2)$ & $(3)$ & $(4)$ \\
& $100 / 100$ & $99 / 95$ & $97 / 85$ & $93 / 75$ \\
\hline & & & & \\
Telefonía tradicional & & & & \\
Costos medios & & & & \\
Acceso & 3.065 & 3.065 & 3.065 & 3.065 \\
Conmutación/transmisión & 2.759 & 2.793 & 2.838 & 2.973 \\
Administrativos & 4.087 & 4.087 & 4.087 & 4.087 \\
Total & 9.911 & 9.945 & 9.990 & 10.125 \\
Costo medio por minuto & 3,14 & 3,23 & 3,39 & 3,62 \\
& & & & \\
Ingresos medios & & & & \\
Cargo fijo & 6.886 & 6.891 & 6.888 & 6.970 \\
Cargo variable por minuto & 7,51 & 7,83 & 8,41 & 9,05 \\
& & & & \\
Telefonía IP & & & & \\
Costos medios & & & & \\
Acceso red tradicional & & 3.065 & 3.065 & 3.065 \\
Administrativos red tradicional & 4.087 & 4.087 & 4.087 \\
IP insensible al tráfico & & 3.835 & 3.835 & 3.835 \\
Total & 10.987 & 10.987 & 10.987 \\
Costo medio por minuto & & 1,96 & 1,83 & 1,70 \\
\hline
\end{tabular}

Fuente de los datos: Telefónica CTC. Cálculos de los autores.

Ahora bien, la estructura tarifaria vigente no replica la estructura de los costos medios porque una parte de los costos que no varían con el tráfico se cobran mediante el cargo variable por minuto. Esto se puede apreciar en la parte media del Cuadro $\mathrm{N}^{\circ} 3$ (Telefonía tradicional; ingresos medios). La columna 1 muestra que el cargo fijo por línea es \$6.886 (contra \$9.911 de costos medios totales que no varían con el tráfico). La contrapartida es que el cargo promedio por minuto es más alto: \$7,51 contra \$3,14. Las siguientes columnas (2 a 5) muestran cómo variaría el cargo fijo y el cargo por minuto a medida que más usuarios emigran a la telefonía IP sobre banda ancha.

El costo de la telefonía IP sobre banda ancha. Los costos de la telefonía IP sobre banda ancha también se pueden separar entre aquellos sensibles al tráfico y aquellos que no lo son. Para describir estos costos, conviene mirar la Figura $N^{\circ}$ 8. Primero, se aprecia que una empresa de telefonía IP sobre banda ancha debe invertir en una plataforma (compuesta por un ga- 
teway (MGW) un soft switch (SS) y un application server (AS)). Segundo, al otro extremo, en el hogar de cada usuario es necesario instalar un adaptador telefónico (AT). Tercero, la telefónica IP tiene que gastar en enlaces que, por un lado, comuniquen al proveedor de Internet (ISP) del usuario con su plataforma; y por el otro, que comuniquen a la plataforma con el resto de las redes en sus respectivos PTR. Por último, una empresa IP incurre en costos de administración: overhead, gastos de marketing, gastos de cobranza, atención de clientes, etc.

Los costos también se pueden dividir entre aquellos que varían con el tráfico y aquellos que no varían con el tráfico. Los costos que varían con el tráfico son tres, y se muestran en el Cuadro $\mathrm{N}^{\circ} 4(\mathrm{a})$ :

- $\quad$ Todo tráfico de salida debe ser conducido desde el ISP hacia la plataforma y de manera similar con el de entrada. Telefónica CTC estima que el costo de esta conexión es $\$ 0,63$ por minuto.

- $\quad$ El tráfico que va hacia otras redes y servicios debe ser transformado en el gateway desde el protocolo IP hacia el protocolo de telefonía tradicional (TDM); y la operación inversa se debe hacer con el tráfico que ingresa a la red IP. Telefónica CTC estima que el costo de esta función de transformación es $\$ 1,10$ por minuto.

- $\quad$ El tráfico que va hacia otras redes y servicios o llega desde ellas debe ser conducido desde y hacia el gateway mediante los así llamados enlaces E1. Telefónica CTC estima que el costo de esta función es $\$ 0,29$ por minuto.

FIGURA N N $^{\circ} \quad$ COMPONENTES DE LA RED DE TELEFONÍA IP

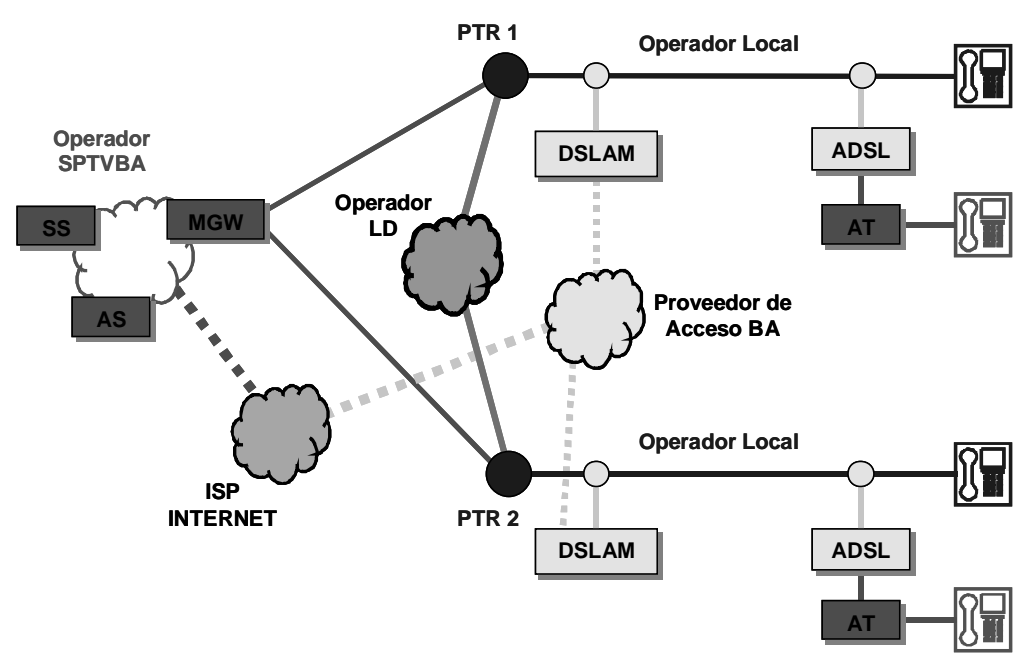


CUADRO N ${ }^{\circ}$ 4: $\quad$ COSTOS DE LA TELEFONÍA IP SOBRE BANDA ANCHA

(a)

Costos medios por minuto de tráfico

(en $\$ / \mathrm{min}$ )

Enlaces con ISP

0,63

Transformación en Gateway

1,10

Enlaces a PTRs

0,29

(b)

Costos medios mensuales invariantes con el tráfico

Costo por línea

Inversión informática ${ }^{1}$

Inversión administración ${ }^{2}$

Materiales y útiles

Comercialización y servicio cliente ${ }^{3}$

Cobranza, recaudación y facturación ${ }^{4}$

Gastos generales ${ }^{5}$

Atención a clientes 6

Total

\$ \%

$1.809+47$

$60 \quad 2$

90

$522 \quad 13$

$519 \quad 14$

$365 \quad 10$

$551 \quad 14$

3.835100

Notas. (1) Inversión informática: incluye hardware, software, instalación e implantación. (2) Inversión administración: incluye inversión inmobiliaria y equipamiento de oficinas. (3) Comercialización y servicio cliente: incluye publicidad, marketing, servicios logísticos, plataforma telefónica para atender a los clientes. (4) Cobranza, recaudación y facturación: sistemas dedicados a facturación y emisión de boletas. (5) Gastos generales: incluye energía, aseo, vigilancia, seguros. (6) Atención a clientes: red de oficinas atención a público con servicios telefónicos y computacionales.

Fuente: Telefónica CTC.

Es importante notar que la empresa IP incurre en costos adicionales sensibles al tráfico: los cargos de acceso en telefónicas locales y móviles, y los enlaces para llevar tráfico a ciudades distintas de la que acoge a la telefónica IP. Los cargos de acceso no se deben incluir en esta evaluación social porque el costo que generará el tráfico que ingresa desde la red IP, o el que sale hacia ella, ya está considerado en los costos de la telefonía tradicional. De manera similar, los enlaces para llevar tráfico desde la ciudad de origen de la telefónica IP hacia otras ciudades de Chile, se ocupan con o sin telefonía IP sobre banda ancha y por lo tanto corresponde excluirlos de la evaluación social. 
Ahora bien, sea $V_{\text {ip }}$ el tráfico total por la red IP, $\mu_{L}$ la fracción del tráfico que es local y $\lambda$ la fracción del tráfico local que ocurre entre usuarios servidos por la telefónica IP (y que, por lo tanto, nunca es transformado a señal de voz tradicional). En ese caso, el costo promedio por minuto es

$$
\begin{aligned}
& \mu_{L} \cdot \lambda \cdot \$ 0,63 \\
& +\mu_{L} \cdot(1-\lambda)(\$ 0,63+\$ 1,10+\$ 0,29) \\
& +\left(1-\mu_{L}\right)(\$ 0,63+\$ 1,10+\$ 0,29) .
\end{aligned}
$$

El primer término es el costo por minuto del tráfico que nunca deja la red IP. El segundo término es el tráfico local que deja la red IP. Y el último término es el costo causado por el resto del tráfico que viaja hacia otras redes.

El parámetro $\mu_{L}$ es igual al inverso de la expresión (5.5). Por otro lado, no tenemos información sobre el parámetro $\lambda$. Supondremos lo siguiente:

Supuesto 3. Si una fracción $\lambda$ del tráfico total (excluyendo a la Internet conmutada) emigra hacia la voz sobre banda ancha, entonces una fracción $\lambda$ del tráfico local ocurre entre telefónicas IP.

El Cuadro $\mathrm{N}^{\circ} 3$ (telefonía IP sobre banda ancha, costo medio por minuto) muestra el costo promedio por minuto de la telefonía IP sobre banda ancha en cada uno de los tres escenarios. Nótese que éste cae a medida que crece el tráfico de la red IP. La razón es que mientras más tráfico emigra, una fracción menor de los minutos de tráficos locales deja la red IP, y por ende el costo por minuto cae. Más importante aún, el costo por minuto de la voz sobre IP es más bajo.

Pasemos ahora a los cargos que no dependen del tráfico. Telefónica CTC (2004) diseñó una empresa IP para atender a 122.462 clientes. El desglose del costo medio que no varía con el tráfico se muestra en el Cuadro 4(b) y alcanza a $\$ 3.835$ mensuales.

\subsection{Resultados}

\subsubsection{La evaluación social}

El cálculo. La parte superior del Cuadro $\mathrm{N}^{\circ} 5$ (“Costos antes de IP”) muestra el costo antes de la introducción de la telefonía IP sobre banda ancha, es decir cuando todo el tráfico es cursado por la red de telefonía fija. Primero mostramos el costo medio por línea. Distinguimos entre clientes que 
CUADRO N N $^{\circ}$ LA EVALUACIÓN SOCIAL DE LA INTRODUCCIÓN DE LA TELEFONÍA IP SOBRE BANDA ANCHA

\begin{tabular}{|c|c|c|c|}
\hline Clientes / tráfico $\rightarrow$ & $\begin{array}{c}(1) \\
99 / 95\end{array}$ & $\begin{array}{c}(2) \\
97 / 85\end{array}$ & $\begin{array}{c}(3) \\
93 / 75\end{array}$ \\
\hline Costos antes de IP & & & \\
\hline $\begin{array}{l}\text { Por línea (en pesos) } \\
\text { Clientes que permanecen }{ }^{1}\end{array}$ & 11.996 & 11.851 & 11.735 \\
\hline Clientes que migran ${ }^{2}$ & 19.521 & 16.435 & 14.951 \\
\hline Promedio & 12.081 & 12.081 & 12.081 \\
\hline $\begin{array}{l}\text { Costo total } \\
\text { (en millones de pesos) }\end{array}$ & $36.035,1$ & $36.035,1$ & $36.035,1$ \\
\hline $\begin{array}{l}\text { Costos con IP } \\
\text { Por línea (en pesos) }\end{array}$ & & & \\
\hline Clientes que permanecen & 12.090 & 12.085 & 12.228 \\
\hline Clientes que migran & 16.979 & 14.791 & 13.722 \\
\hline $\begin{array}{l}\text { Costo total } \\
\text { (en millones de pesos) }\end{array}$ & $36.226,4$ & $36.451,6$ & $36.954,6$ \\
\hline $\begin{array}{l}\text { Evaluación social } \\
\text { Pérdida social mensual } \\
\text { (en millones de pesos) } \\
\text { Pérdida social mensual } \\
\text { (en dólares) }\end{array}$ & 351.092 & 764.275 & 1.687 .204 \\
\hline
\end{tabular}

Notas: (1) Corresponde al costo promedio que generaban aquellas líneas que permanecen en la telefonía tradicional antes de la introducción de la telefonía IP sobre banda ancha. (2) Corresponde al costo promedio que generaban aquellas líneas que migran hacia la voz sobre banda ancha antes de la introducción de la telefonía IP sobre banda ancha.

Fuente de los datos: Telefónica CTC. Cálculos de los autores.

permanecen en la red tradicional y no emigrarán a la telefonía IP sobre banda ancha; y clientes que emigrarán hacia la telefonía IP sobre banda ancha. Se aprecia que el costo total promedio por línea es $\$ 12.080$, lo que da un costo total de cursar todo el tráfico de \$36.034,2 millones. Por razones obvias, en cada caso, los clientes que eventualmente emigrarán generan costos más altos.

La parte media del Cuadro No 5 ("Costos con IP") muestra los costos con telefonía IP sobre banda ancha. Los clientes que permanecen siguen siendo atendidos por la telefónica tradicional, pero los clientes que emigran son atendidos por una telefónica IP. 
Nótese que el costo medio por cliente IP cae en todos los casos. Por ejemplo, el costo medio de los 33.718 clientes que emigran en el caso 99/95 cae desde \$19.521 hasta \$16.979, es decir \$2.452. Esto es consecuencia de que el costo variable de la telefonía IP sobre banda ancha es menor. Por supuesto, la ganancia media por cliente va disminuyendo a medida que progresivamente trasladamos a clientes que llaman menos en promedio hacia la telefonía IP sobre banda ancha. Tanto así que, cuando emigran hacia la telefonía IP sobre banda ancha el 7\% de los usuarios y el 25\% del tráfico, la diferencia de costos cae a $\$ 1.229$ (\$14.951 contra \$13.722).

La contrapartida de los menores costos que generan los clientes de alto tráfico en la telefonía IP sobre banda ancha, son los mayores costos por línea de quienes se quedan en la telefonía tradicional. Como ya se vio, en todos los casos la migración aumenta los costos medios de los clientes de bajo tráfico. Por ejemplo, se aprecia en el Cuadro $N^{\circ} 5$ que cuando emigra el 5\% del tráfico el costo medio por línea de los clientes que permanecen aumenta desde \$11.996 (columna 1, fila “Costos antes de IP, clientes que permanecen”) hasta $\$ 12.090$ (columna 1, fila “Costos con IP, clientes que permanecen”), o \$94; cuando el tráfico cae 15\% el aumento es desde \$11.851 hasta $\$ 12.085$, o $\$ 234$.

Cuando se suman ahorros y aumentos de costos, se llega a la conclusión que en todos los casos el costo total aumenta con la introducción de la telefonía IP sobre banda ancha. La última línea reporta la pérdida social en dólares. Ésta va desde US\$351.092 mensuales si sólo emigra el 5\% del tráfico, hasta US\$1.687.204 mensuales si el 25\% del tráfico emigra hacia la voz sobre banda ancha. Líneas abajo examinaremos qué tan robusta es esta conclusión. De hecho, concluiremos que el efecto sobre el bienestar social es, a pesar de todo, incierto. Por ahora, simplemente examinemos la aritmética que está detrás de este resultado.

La aritmética de la pérdida social. La ventaja de la telefonía IP sobre banda ancha es que los costos variables por minuto son más bajos. Por eso, la disminución de costos por línea es apreciable cuando emigran clientes que llaman mucho. Sin embargo, la telefonía IP sobre banda ancha también incurre en costos administrativos y de redes, que son más altos que los costos medios de la conmutación/transmisión en telefonía fija ${ }^{16}$. Por cierto, si nos restringimos a los clientes que emigran, los ahorros por menores

${ }^{16}$ Esto se aprecia en el Cuadro $\mathrm{N}^{\circ} 2$, columna 1. El costo medio de la conmutación/transmisión que no es sensible al tráfico es \$2.759 por línea cuando todo el tráfico se cursa por la red fija. Los usuarios que migran a la telefonía IP sobre banda ancha ya no incurren en este costo. Sin embargo, cada línea de telefonía IP sobre banda ancha genera \$4.298 de costos que no varían con el tráfico. 
costos variables son suficientes para llegar a costos por línea más bajos. Pero, desde el punto de vista de la evaluación social, este ahorro no es suficiente para compensar los mayores costos medios de la red tradicional una vez que el tráfico emigra.

\subsubsection{El efecto distributivo}

Una evaluación social examina costos y beneficios netos. Sin embargo, un aspecto de interés cuando se analiza la introducción de la telefonía IP sobre banda ancha son los efectos distributivos que ella genera. Para calcularlos, utilizamos las expresiones (5.3) y (5.4) y las reportamos en el Cuadro $\mathrm{N}^{\circ}$ 6. La parte superior del cuadro (Ingreso por línea, antes de IP) reporta los ingresos por línea generados antes de la telefonía IP sobre banda ancha por los clientes que permanecen y que emigran. Se puede apreciar que estos ingresos medios provienen de un cargo fijo de $\$ 6.886$ por línea y un cargo variable por minuto de $\$ 7,51$. La parte media del cuadro ("Ingreso por línea, con IP”) reporta los ingresos generados en promedio por cada línea con telefonía IP sobre banda ancha. El efecto distributivo se reporta en la parte inferior del cuadro (sección "Efecto distributivo").

La primera fila de la sección "Efecto distributivo" muestra que el mayor ingreso medio que debe generar una línea que permanece en la telefonía tradicional aumenta a medida que tráfico y clientes emigran hacia la telefonía IP sobre banda ancha. Esto refleja en parte los mayores costos medios pero, sobre todo, que los clientes que emigran pagaban más que el costo medio de su línea.

Por ejemplo, se aprecia en el Cuadro $\mathrm{N}^{\circ} 6$ que una línea que permanece en la telefonía fija debe generar \$213 más en promedio con telefonía IP sobre banda ancha, a pesar de que, tal como se deduce del Cuadro $\mathrm{N}^{\circ} 5$, el costo medio por línea aumenta sólo en \$94. Por lo mismo, la caída del ingreso generado por una línea que emigra hacia la telefonía IP sobre banda ancha es bastante mayor que la caída en costos — \$12.912 contra \$2.542—.

Si bien los montos promedio por línea no parecen muy grandes, los montos totales no son muy pequeños. Por ejemplo, se aprecia en el Cuadro $\mathrm{N}^{\circ} 6$ que cuando emigra el 5\% del tráfico, las líneas que permanecen deben generar US\$1,15 millones de dólares más por mes; cuando el tráfico cae 15\% el aumento es de US\$2,88 millones por mes; y cuando cae 25\%, el aumento es de US $\$ 4,77$ millones por mes. La moraleja es que, si bien el efecto sobre el bienestar social de la introducción de la telefonía IP sobre banda ancha es incierto (precisaremos esta afirmación a continuación), el efecto distributivo es apreciable y robusto. 
CUADRO No 6: EL EFECTO DISTRIBUTIVO DE LA INTRODUCCIÓN DE LA TELEFONÍA IP SOBRE BANDA ANCHA

$\begin{array}{cccc}\text { Clientes / tráfico } \rightarrow & (1) & (2) & (3) \\ & 99 / 95 & 97 / 85 & 93 / 75\end{array}$

Ingreso por línea, antes de IP

(en pesos)

Cargo fijo

6.886

6.886

6.886

Cargo variable por minuto

7,51

7,51

7,51

Clientes que permanecen ${ }^{1}$

11.877

11.530

11.252

Clientes que migran ${ }^{2}$

29.891

22.504

18.951

Ingreso por línea después de IP

(en pesos)

Clientes que permanecen

$$
\text { Cargo fijo }
$$

6.891

6.888

6.970

Cargo variable por minuto

7,83

8,41

9,05

12.090

12.085

12.228

Clientes que migran

16.979

14.791

13.722

Aumento de ingreso bajo tráfico

Caída de ingreso telefonía $\mathrm{IP}^{3}$

12.912

7.714

5.226

Efecto distributivo

En millones de pesos

Aumento de ingreso por línea (fijo)

626,7

435,4

191,3

Pérdida social

En dólares

Aumento de ingreso por línea (fijo)

Caída de ingreso por línea (IP)

Pérdida social

1.149 .907
798.815
351.092

2.882.831

4.767 .513

2.118 .556

764.275
$2.598,3$

$1.678,8$

919,5

Nota: (1) Corresponde al ingreso promedio que generaban aquellas líneas que permanecen en la telefonía tradicional antes de la introducción de la telefonía IP sobre banda ancha. (2) Corresponde al ingreso promedio que generaban aquellas líneas que migran hacia la voz sobre banda ancha antes de la introducción de la telefonía IP sobre banda ancha. (3) La “caída de ingreso telefonía IP” es el menor ingreso que generarán las líneas IP de voz sobre banda ancha suponiendo que todos los menores costos se traspasan a tarifas.

Fuente de los datos: Telefónica CTC. Cálculos de los autores. 


\subsubsection{Robustez y sensibilidad}

¿Qué tanto se puede confiar en los resultados que mostramos líneas arriba? Argumentaremos a continuación que no se puede afirmar categóricamente que el bienestar social caerá con la introducción de la telefonía IP sobre banda ancha. Sin embargo, y al mismo tiempo, si la estimación hubiera arrojado un aumento del bienestar social de orden de magnitud similar, tampoco se podría afirmar que lo aumentará. Puesto en término precisos: un error de medición pequeño bastaría para que no se pudiera rechazar las dos posibles hipótesis nulas:

- La telefonía IP sobre banda ancha aumenta el bienestar social.

- L La telefonía IP sobre banda ancha disminuye el bienestar social.

Por el contrario, es posible concluir con razonable confianza que el resultado sobre el efecto distributivo es robusto.

La afirmación anterior podría sorprender, porque es claro que los cálculos que reportamos no permiten deducir directamente intervalos de confianza. Los cálculos que presentamos son estimaciones de, por un lado, la disminución del costo total de la telefonía tradicional cuando emigran usuarios y tráfico, llamémosla $\Delta C_{t} ; \mathrm{y}$, por el otro, del costo total de atender a esos usuarios y cursar el tráfico por telefonía IP sobre banda ancha, llamémoslo $C_{\text {ipp }}$. Pero igual podemos formarnos una idea del orden de magnitud del error de medición que nos haría aceptar o rechazar estas hipótesis.

Supongamos que $\Delta C_{t}$ y $C_{\text {ip }}$ son los valores verdaderos, pero que nosotros obtuvimos estimaciones con error

$$
\begin{aligned}
& \Delta \tilde{C}_{t}=\Delta C_{t}+\varepsilon_{t} \\
& \mathrm{y} \\
& \tilde{C}_{\mathrm{ip}}=\Delta C_{\mathrm{ip}}+\varepsilon_{\mathrm{ip}},
\end{aligned}
$$

donde $\varepsilon_{t}$ y $\varepsilon_{\mathrm{ip}}$ son errores de medición normales, insesgados e independientes, y ambos con la misma varianza $\sigma^{2}$ (este supuesto sólo es para simplificar; lo relevante es que se trata de varianzas del mismo orden de magnitud). En ese caso, el cambio de bienestar social $\Delta \tilde{C}_{t}-\tilde{C}_{\text {ip }}$, se distribuye normal con media $\Delta C_{t}-\Delta C_{\text {ip }}$ y varianza $2 \sigma^{2}$.

Si conociéramos $2 \sigma^{2}$ podríamos testear directamente la hipótesis nula, la telefonía IP sobre banda ancha no disminuye el bienestar social, o $\Delta C_{t}-\Delta C_{\mathrm{ip}} \geq 0$. En ese caso, 


$$
\frac{\Delta \tilde{C}_{t}-\Delta \tilde{C}_{i p}}{\sqrt{2 \sigma^{2}}}
$$

se distribuye normal bajo la hipótesis nula. En general, dada una observación $\Delta \tilde{C}_{t}-\Delta \tilde{C}_{\mathrm{ip}}<0$, una varianza pequeña justificará rechazar la hipótesis nula. Por el contrario, una varianza suficientemente grande justificaría aceptar la hipótesis nula. Nuestro punto es que, muy posiblemente, el error de medición es "grande".

El Cuadro $N^{\circ} 7$ muestra los valores máximos de $\sqrt{2} \sigma^{2}$, tales que, dada la estimación del cambio del bienestar social, rechazaríamos la hipótesis nula "la telefonía IP sobre banda ancha no disminuye el bienestar social” a los niveles de confianza estándares —-1\%, 5\% y 10\%-. Así, por ejemplo, para rechazarla al $1 \%$ de confianza cuando emigra el $5 \%$ del tráfico, $\sqrt{2 \sigma^{2}}$ tendría que ser \$82,1 millones o menos. ¿Qué tan grandes son estos números. Nótese que si $\sqrt{2} \sigma^{2}=\$ 82,1$ millones, entonces

$$
\sigma=\frac{\$ 82,1}{\sqrt{2}} \approx \$ 58,06 .
$$

La segunda parte del Cuadro $\mathrm{N}^{0} 7$ indica los valores críticos de $\sigma$ máximos tales que se rechaza la hipótesis nula en millones de pesos. Nótese que la disminución de costo de la telefonía tradicional cuando emigra el 5\%

CUADRO N 7: $\quad$ ERRORES DE MEDICIÓN CRÍTICOS

\begin{tabular}{lrrrr}
\hline & & \multicolumn{3}{c}{ Niveles de confianza } \\
\cline { 4 - 5 } Millones de $\$$ & Tráfico que migra & $1 \%$ & $5 \%$ & $10 \%$ \\
& & & \\
Valores máximos de $\sqrt{2 \sigma^{2}}$ & $5 \%$ & 82,1 & 115,9 & 148,3 \\
(millones de pesos) & $15 \%$ & 178,8 & 252.4 & 322,9 \\
& $25 \%$ & 394,6 & 557,3 & 712,8 \\
Desviación estándar crítica $\sigma_{\text {Crítico }}$ & $5 \%$ & 58,1 & 82,0 & 104,9 \\
(millones de pesos) & $15 \%$ & 126,4 & 178,5 & 228,3 \\
& $25 \%$ & 279,1 & 394,1 & 504,0 \\
Errores de medición críticos & $5 \%$ & 0,15 & 0,22 & 0,28 \\
$\sigma_{\text {Crítico }} / \Delta C_{t}$ & $15 \%$ & 0,07 & 0,10 & 0,13 \\
& $25 \%$ & 0,08 & 0,11 & 0,14 \\
$\sigma_{\text {Crítico }} / C_{i p}$ & $5 \%$ & 0,10 & 0,14 & 0,18 \\
& $15 \%$ & 0,06 & 0,08 & 0,10 \\
& $25 \%$ & 0,06 & 0,09 & 0,11 \\
\hline
\end{tabular}


del tráfico es $\Delta C_{t}=\$ 379,9$ millones, mientras que el costo de servir a ese tráfico con telefonía IP sobre banda ancha es $C_{i p}=\$ 572,5$ millones. Vale decir, la desviación estándar crítica es alrededor de un orden de magnitud menor.

La última parte del Cuadro № 7 compara al $\sigma$ "crítico" con las estimaciones de $\Delta C_{t}$ y $C_{\mathrm{ip}}$ que reportamos líneas arriba. En cada caso se computan

$$
\begin{aligned}
& \frac{\Delta C_{t}}{\sigma} \\
& \mathrm{y} \\
& \frac{C_{\text {ip }}}{\sigma}
\end{aligned}
$$

y así tenemos una medida del máximo error de medición que justifica aceptar la hipótesis nula. La tercera parte del Cuadro $\mathrm{N}^{\mathrm{o}} 7$ muestra el error de medición máximo de cada componente tal que la hipótesis nula se acepta. Se puede apreciar que, según sea el caso, éste va desde 0,06 (ó 6\%) hasta 0,28 (ó 28\%). Creemos justificado afirmar que tales errores de medición son, por decir lo menos, modestos, por lo menos si se los compara con las discrepancias habituales en los estudios de costos cuando se fijan las tarifas de servicios públicos regulados ${ }^{17}$.

Al mismo tiempo, los efectos distributivos que calculamos son robustos. Es claro que la voz sobre banda ancha beneficia a quienes más llaman, porque el costo por minuto es menor. Al mismo tiempo, en tanto existan economías de escala en telefonía tradicional, la caída de usuarios y tráfico tiene que aumentar los costos medios. Estos efectos se refuerzan porque los decretos tarifarios les cargan parte de los costos que no dependen del tráfico a los cargos por minuto.

\subsubsection{Objeciones y comentarios}

“La empresa eficiente usaría tecnología IP”. Una crítica que hemos recibido es que a esta altura la empresa eficiente debiera usar tecnología IP, que supuestamente es más barata. ¿Cambiarían los resultados que reportamos?

${ }^{17}$ Nótese que la estimación del cambio de bienestar no es más precisa si se considera el caso en que migra más tráfico que el 5\%. La forma en que se calcula el modelo tarifario implica que no se agregan muestras independientes de usuarios para construirlo; se supone fijo el número de usuarios y el tráfico, y luego se construye una empresa eficiente para servirlos. 
Aún es una cuestión debatida si la tecnología de la empresa eficiente debe ser IP, disputa que deberá zanjar el próximo estudio tarifario. Pero si los datos existieran, el cálculo se haría de la misma forma: se calcularía el costo de cursar todas las llamadas por una empresa eficiente, que esta vez usa tecnología IP; luego se introduciría la voz sobre banda ancha; se calcularía el cambio del costo de la empresa eficiente; y, finalmente, calcula el costo de prestar voz sobre banda ancha. En otras palabras, el cálculo es

$$
C_{t}^{0}-\left(C_{t}^{1}+C_{\mathrm{ip}}\right)=\Delta C_{t}-C_{\mathrm{ip}},
$$

pero esta vez la empresa eficiente usa tecnología IP.

Sin embargo, mientras la empresa eficiente que usa tecnología IP tenga economías de escala, seguramente se volvería a concluir que cualquiera de las dos hipótesis nulas se puede aceptar. El punto de fondo es que si bien las llamadas de quienes no emigran a telefonía IP serían más baratas ( $C_{t}^{1}$ sería más bajo), también lo serían las llamadas antes de introducir voz sobre banda ancha hecha por la empresa eficiente que conmuta IP, $C_{t}^{0}$. Por eso, el resultado no depende del nivel de costos de la empresa eficiente sino del cambio por la pérdida de economías de escala.

En todo caso, es conveniente notar qué cálculo no hay que hacer: calcular el costo de una empresa eficiente que cursa todas las llamadas con tecnología tradicional; y luego comparar con los costos si se introduce la voz sobre banda ancha y se sustituye la tecnología de la empresa eficiente por telefonía IP. Eso es mezclar peras con manzanas y, peor aún, viola la lógica de la empresa eficiente - la empresa eficiente usa la misma tecnología eficiente antes y después de la introducción de voz sobre banda ancha-.

Elasticidades igual a cero. Una segunda causa de aprensión podría ser el hecho que suponemos demandas perfectamente inelásticas. Con ello, nuestra evaluación social se reduce a una comparación de costos. La pregunta relevante, sin embargo, es si haría una diferencia cuantitativa considerar una elasticidad mayor que cero en valor absoluto.

Relativo a lo que estimamos suponiendo el tráfico fijo, la inclusión de los triángulos de bienestar aumentaría la ganancia de quienes emigran. La pérdida estimada de quienes permanecen en la telefonía tradicional podría aumentar o caer: por un lado, al suponer la cantidad fija se sobrestima la pérdida al ignorar que los consumidores responderán al alza de precios disminuyendo su cantidad demandada. Pero, por el otro lado, la caída del tráfico aumenta aun más la pérdida de economías de escala. 
En cualquier caso, pensamos que el resultado de la evaluación social sería muy parecido porque relativo a los rectángulos, los triángulos debieran ser pequeños. Porque supóngase que las elasticidades relevantes fueran iguales a -1 (bastante mayores que las estimadas en los estudios que acompañaron al estudio tarifario). Una caída de $20 \%$ de la tarifa por minuto aumentaría el tráfico en $20 \%$. El tamaño del rectángulo, que nuestra estimación computa, es

$$
20 \% \times 100 \%=20 \% \text {, }
$$

Mientras que el triángulo de ganancia de bienestar es aproximadamente

$$
\frac{20 \% \times 20 \%}{2}=20 \%,
$$

vale decir $\frac{1}{10}$ del efecto que computamos nosotros — es decir, cae dentro del rango del error de medición que es razonable suponer en este caso-.

Bandas anchas. Nótese que todos los cálculos suponen que quienes emigran ya habían contratado una conexión de banda ancha. Este supuesto no es irrazonable, porque el número de clientes de banda ancha necesario para hacer caer el tráfico en $25 \%$ es 321.024 ó $10,76 \%$ del total, mientras que el número de conexiones de banda ancha en junio de 2004 era equivalente al 13\% de las líneas. Sin embargo, en la práctica seguramente habrá clientes que teniendo una banda ancha no emigran y, por otro lado, clientes que contratan una banda ancha para emigrar. Es claro que, en ese caso, el costo social de la emigración sería aun mayor, porque es necesario instalar más conexiones de banda ancha. Al mismo tiempo, los beneficios aumentan en el valor de la banda ancha para quienes la contraten, pero menos que el costo.

Larga distancia. Uno de los beneficios de la voz sobre banda ancha, que este trabajo no cuantifica, son los mayores excedentes que obtendrían los consumidores por el menor precio de las llamadas de larga distancia. Las telefónicas que ofrecen voz sobre banda ancha cobran tarifas más bajas, sobre todo al extranjero.

Sin desconocer estos beneficios, es improbable que el incluirlos cambie las conclusiones de este trabajo. En efecto, se aprecia en el Cuadro 
$\mathrm{N}^{\mathrm{o}} 1$ que el tráfico de larga distancia internacional de salida era en abril de 2004 apenas el 0,99\% del tráfico local; el tráfico de larga distancia nacional representaba el 7,59\% del tráfico total. Más aún, según antecedentes de Telefónica CTC, no más del 40\% de este tráfico proviene de hogares. Por lo tanto, es improbable que la inclusión de la larga distancia en los cálculos cambie la conclusión, en el sentido que el efecto sobre el bienestar de la introducción de la voz sobre banda ancha es ambiguo. Más aún, es conveniente notar que si se tiene una conexión de banda ancha, ya es posible acceder a tarifas de larga distancia más bajas a través de empresas como Skype.

Costo de la telefónica que provee voz sobre banda ancha. La estimación de los costos de la telefónica IP que usamos en nuestros cálculos es de CTC y, por razones obvias, no pasó por la Subtel ni tampoco por el comité de peritos. Sería conveniente, por tanto, ver cuánto varían los resultados con estimaciones distintas de ese costo.

El trabajo de El Hureimi (2005, p. 11) incluye una estimación de costos de una telefónica IP sobre banda ancha entregada por Redvoiss, una empresa que vende servicios de voz sobre banda ancha. Redvoiss estima que el costo de la telefonía sobre banda ancha es $\$ 747$ menor que el supuesto por CTC (\$3.088 contra \$3.835) ${ }^{18}$.

Con este costo menor la pérdida social mensual cae desde US\$351.092 a US\$ 304.877 si emigra el 5\% del tráfico; desde US\$764.275 a US\$559.113 si emigra el 15\% del tráfico; y desde US\$1.687.204 a US\$1.247.195 si emigra el 25\% de tráfico. Por lo tanto, ninguna de nuestras conclusiones cambia.

Comentarios a un estudio reciente. Un estudio reciente de El Hureimi (2005) encuentra que los beneficios anuales de la voz sobre banda ancha serían US\$964 millones de dólares por año. Este número es enorme. Por ejemplo, los precios fijados por el estudio tarifario de Telefónica CTC implican que la empresa modelo generaría ingresos totales anuales por US\$970 millones. Vale decir, según este estudio, la introducción de la telefonía IP sobre banda ancha generaría un beneficio neto anual igual a todos los costos de la empresa eficiente ${ }^{19}$. Este número también es similar a la ganancia que obtuvo Chile por haber firmado los acuerdos de libre comercio con

${ }^{18} \mathrm{El}$ valor reportado por El Hureimi fue dividido por 1,19, para sacarle el IVA.

${ }^{19}$ Para llegar a los ingresos anuales de la empresa eficiente se multiplicaron los $\$ 36.035,1$ millones de ingresos totales mensuales por 12, y se dividió por el tipo de cambio que supone El Hureimi (\$530 por dólar). Luego se multiplicó por 1,19 para llevarlo a valores con IVA. 
Estados Unidos y la Unión Europea. En efecto, Chumacero et al. (2004) estiman que los dos acuerdos sumados aumentarán permanentemente el PGB chileno en $1 \%$ — cifra de magnitud similar al beneficio estimado por El Hureimi (2005) para la voz sobre banda ancha-.

¿A qué se deben las diferencias entre este estudio y el nuestro? Conviene partir señalando que El Hureimi ejecuta un ejercicio distinto, a saber, calcula el beneficio de reemplazar toda la telefonía fija con voz sobre banda ancha. Esto implica instalarles bandas anchas a todas las líneas y eliminar la telefonía tradicional. Por contraste, nuestro ejercicio supone que las dos redes continúan coexistiendo.

Con todo, es conveniente examinar por qué El Hureimi (2005) obtiene beneficios tan altos. De un lado, él indica que la voz sobre banda ancha (incluyendo la electrónica de banda ancha), se puede proveer a \$8.357 mensual por conexión ${ }^{20}$. Esto se puede comparar con el cargo fijo de $\$ 9.202$ que el decreto tarifario le fijó a Telefónica CTC y los \$14.376 que, el mismo decreto estimó, es el ingreso mensual por línea que necesita la empresa eficiente para autofinanciarse y obtener una rentabilidad normal ${ }^{21}$. Del otro lado, la caída del precio de la voz y la banda ancha generan aumentos de la cantidad demandada.

¿Por qué sería tanto más barata la voz sobre banda ancha? Conviene señalar que no es porque los costos de la compañía de teléfonos IP sobre banda ancha sean mucho más bajos. En efecto, como se dijo líneas arriba, El Hureimi presenta una estimación, hecha por la empresa Redvoiss, según la cual el costo adicional de la empresa IP sería $\$ 3.675$, los que se comparan con los \$4.563 estimados por Telefónica CTC, el valor que presentamos en el Cuadro 4 ajustado para incluir el IVA ${ }^{22}$. Si bien los $\$ 888$ de diferencia equivalen al 24\% de los costos de una telefónica IP estimados por Redvoiss, son insuficientes para explicar la diferencia de costo por línea.

En realidad, la ventaja de la telefonía IP sobre banda ancha proviene de suponer que basta un par de cobre y una conexión de banda ancha para servir a cuatro usuarios; lo que, grosso modo, implica dividir por cuatro el

\footnotetext{
${ }^{20}$ Este monto incluye IVA.

${ }^{21}$ Nótese, además, que los \$8.357 incluyen el costo de la conexión de banda ancha.

${ }^{22}$ Cabe mencionar, en todo caso, que el trabajo supone que la empresa IP no incurre costos que varíen con el tráfico - consecuencia de suponer que la voz sobre banda ancha sustituye completamente a la red tradicional. Sin embargo, las conexiones a móviles siguen necesitando enlaces E1. Nótese, además, que, según El Hureimi, la estimación de Redvoiss supone que la voz sobre banda ancha se masifica, y es posible, por tanto, que se estén aprovechando economías de escala.
} 
costo de la empresa eficiente ${ }^{23}$. Si fuera factible, este cambio sería sin lugar a dudas muy conveniente y debiera ser recogido en las siguientes fijaciones de tarifas. Creemos, sin embargo, que a lo menos se justifica cierto escepticismo mientras el estudio correspondiente no se haga.

\section{Conclusión}

Este trabajo concluye que a lo menos es incierto que la telefonía IP sobre banda ancha aumente el bienestar social. Esto podría sorprender, porque supuestamente la voz sobre banda ancha hace más competitivo al mercado telefónico y la competencia aumenta el bienestar. ¿Qué explica esta aparente paradoja?

En la mayoría de los mercados una liberalización permite obtener un free lunch competitivo: los precios caen, la cantidad intercambiada aumenta y el bienestar social aumenta. Todos los consumidores pagan menos, se materializa una ganancia de eficiencia y las rentas que obtenían algunos antes de la liberalización se redistribuyen hacia los consumidores. Por ejemplo, cuando se liberalizó la larga distancia en 1994 las tarifas cayeron y el tráfico se duplicó casi de un día para otro. Es cierto que la empresa que hasta entonces tenía el monopolio perdió sus utilidades, pero esto fue más que compensado por las ganancias de los consumidores.

Sin embargo, en este caso no se obtiene un free lunch competitivo porque la voz sobre banda ancha no sustituirá por completo a la telefonía tradicional. Muchos usuarios no migrarán, porque para hacerlo es necesario pagar una conexión de banda ancha y para muchos no vale la pena pues su tráfico no lo justifica ${ }^{24}$. Por eso, muchos usuarios continuarán usando la

${ }^{23}$ Es conveniente notar, además, dos omisiones importantes. Primero, los \$8.357 incluyen sólo el costo de la red de acceso, y no el costo de las inversiones en edificios que son necesarios para instalar los equipos electrónicos que conectan a los pares de cobre con la red de datos. Este costo es una fracción mayoritaria de los costos de conmutación/transmisión que no varían con el tráfico y que se muestran en el Cuadro $\mathrm{N}^{\circ} 3$.

Segundo, para estimar el costo de la empresa de redes, El Hureimi dividió por cuatro el cargo fijo que actualmente cobra Telefónica CTC. Ahora bien, como se vio líneas arriba, más de la mitad del cargo fijo paga los costos administrativos de la empresa eficiente. Por lo tanto, se está suponiendo que los costos administrativos de la empresa que provee la red de acceso también caerán a la cuarta parte.

${ }^{24}$ Se suele argumentar que la competencia en banda ancha es insuficiente y que su precio (alrededor de \$25.000 mensuales) es muy alto. Aunque no tenemos una opinión formada sobre la competitividad del mercado de banda ancha, el punto no es muy relevante aquí, porque bastaría un precio de la banda ancha no mucho mayor que \$5.000 para que la gran mayoría de los usuarios prefirieran seguir siendo servidos por la telefonía tradicional. 
telefonía tradicional y deberán pagar más, por las deseconomías de escala. De esta forma, los precios no caerán para todos, al contrario de lo que ocurre en la mayoría de las liberalizaciones.

Por supuesto, si la penetración de la banda ancha fuera muy alta, tal como en varios países desarrollados, la introducción de la voz seguramente haría migrar a la gran mayoría de los usuarios y obligaría a la empresa tradicional a reconocer la pérdida de capital y bajar sus tarifas. En ese caso, una tecnología más barata (la voz sobre banda ancha) sustituiría a una más cara (la telefonía tradicional) y obtendríamos los efectos estándares de una liberalización. Pero ese no es el caso en Chile, donde la gran mayoría de los hogares no está dispuesto a pagar por una conexión de banda ancha.

Conviene mencionar, en todo caso, que nuestra conclusión no nos parece necesariamente incoherente con que el regulador autorice la entrada de la telefonía IP sobre banda ancha. En nuestra opinión, la legislación vigente permite privilegiar la entrada por sobre el aprovechamiento de las economías de escala ${ }^{25}$. Así, por ejemplo, se permite la superposición de redes, aun cuando se sabe que ésta duplica inversiones ${ }^{26}$.

¿Por qué tiene sentido permitir la entrada aun si se desaprovechan economías de escala? La respuesta suele ser porque la competencia es buena, pero conviene precisar. A esta altura es a lo menos discutible que la entrada haya disminuido los precios directamente, al menos si se trata de clientes residenciales y pequeños. En efecto, aquellas telefónicas que compiten con la empresa regulada suelen cobrar tarifas similares a las que fija la Subtel $^{27}$. Sin embargo, seguramente la entrada ha traído otros beneficios: el regulador cuenta con fuentes alternativas de información que morigeran las asimetrías de información y reducen la así llamada renta de la información que obtiene la empresa regulada ${ }^{28}$; posiblemente la entrada estimula la adopción más rápida de innovaciones tecnológicas que se verían retrasadas si existiera un monopolio; la adopción de nuevas tecnologías también permite aprovechar economías de ámbito entre telefonía y otros servicios como la televisión por cable; y, por último, cuando existen oferentes alternativos mejora la calidad del servicio a los usuarios. Estos beneficios hacen que el aprovechamiento de las economías de escala no sea el único factor a considerar.

${ }^{25}$ Este punto lo desarrollamos en Galetovic y Sanhueza (2001).

${ }^{26}$ No es nuestra intención interpretar el sentido de las leyes. Estamos conscientes de que la entrada de la telefonía IP sobre banda ancha es distinta a la entrada con redes - la telefonía IP sobre banda ancha ocupa activos de otros para llegar al clientey que hay envueltos argumentos legales que sobrepasan nuestras competencias.

${ }^{27}$ Nótese, además, que si la entrada de nuevos competidores implica desaprovechar economías de escala y aumenta las tarifas reguladas, todos pagan precios más altos.

${ }^{28}$ Véase a Gasmi et al. (2002). 
Sin embargo, que la ley permita privilegiar la entrada por sobre las economías de escala no obliga a hacerlo. Y porque la voz sobre banda ancha no es un free lunch competitivo, hay que preguntarse cuáles son los beneficios adicionales que la justifican ${ }^{29}$. Nótese que es dudoso que éstos provengan de asimetrías de información menos intensas entre las empresas reguladas y el regulador. Más allá de que seguramente tales ganancias de información ya se materializaron con las empresas que ya entraron, hay que notar que la voz sobre banda ancha ocupa tecnología muy distinta y complementaria a la de las telefónicas tradicionales. Más aún, la voz sobre banda ancha no reduce la necesidad de regular, por cuanto sigue utilizando los activos de una telefónica tradicional (la red de acceso) y sus servicios (v.gr. mantención, facturación) $)^{30}$.

Así que, seguramente, la principal carta de presentación de la voz sobre banda ancha es que se trata de una tecnología nueva que utiliza Internet. Es importante notar, sin embargo, que se trata en gran medida de una innovación de proceso y no de producto. En efecto, la principal diferencia es que la voz, en vez de ser transportada en forma de señales analógicas y digitales, ahora viaja en paquetes por Internet. Desde el punto de vista del usuario, por tanto, se trata de dos productos similares. Por supuesto, hay otras ventajas, como por ejemplo contratar un número telefónico extranjero. Sería muy conveniente, por tanto, un estudio que estime el beneficio de estos nuevos productos que permite la voz sobre banda ancha.

\section{APÉNDICE}

\section{A. Voz sobre banda ancha tarificada incorrectamente}

En el trabajo suponemos que los emigrantes hacia la telefonía IP continúan pagando el costo medio de la red de acceso. Además, como siguen siendo clientes de la telefónica tradicional, continúan pagando por los servicios administrativos. Sin embargo, algunos argumentan que estos usuarios no deberían continuar pagando el cargo fijo, ya que éste sólo remuneraría costos del servicio telefónico tradicional. En nuestra opinión tal argumento no se sostiene. El par de cobre es necesario para prestar el

${ }^{29}$ No nos parece evidente que la voz sobre banda ancha conduzca a una rebaja apreciable de tarifas en las circunstancias actuales. Las telefónicas IP no son grandes y es posible que también sigan a la tarifa regulada por la Subtel.

30 Más aún, nótese que algunos usuarios de la voz sobre banda ancha usarían la red de acceso de empresas no reguladas. Inevitablemente, surgiría la pregunta de cuánto pueden cobrar estas empresas por el acceso, y seguramente habría que regularlo también. 
servicio de telefonía tradicional, pero también el servicio de telefonía IP sobre banda ancha. Si se deja de pagar por el servicio telefónico tradicional, pero se sigue usando el par de cobre, corresponde seguir pagándolo ${ }^{31}$. En cualquier caso, conviene analizar qué ocurre cuando estos activos se remuneran parcialmente.

\section{A.1 El modelo}

Si la voz sobre banda ancha se introduce en condiciones tales que la empresa sólo puede cobrarle ${\tilde{p_{\mathrm{ip}}}}^{f}<\left[C^{a}(S)+A(S)\right] / S=p_{t}^{f}$ a quienes emigran, el equilibrio es ahora descrito por un vector

$$
\left(\tilde{p}_{t}^{f}, \tilde{p}_{t}^{v}, \tilde{v}_{t},\left(\tilde{S}_{b}-S_{b}\right) ; p_{b}, \tilde{S}_{b} ; \tilde{p}_{\mathrm{ip}}^{f}, p_{\mathrm{ip}}^{v}, v_{\mathrm{ip}}, \tilde{S}_{b}\right) .
$$

Comparado con el caso en que los que emigran siguen pagando todo el cargo fijo, el autofinanciamiento requiere que

$$
\tilde{p}_{t}^{f}>p_{t}^{f}>p_{t}^{f}
$$

Obviamente, los usuarios que no emigran hacia la telefonía IP sobre banda ancha deben pagar una parte adicional de la red de acceso y de los gastos de administración.

La disminución del cargo fijo es un estímulo adicional a la banda ancha. Tal como se aprecia en la Figura A1, la disposición a pagar aumenta aun más y, por consiguiente, más usuarios emigran hacia la telefonía IP sobre banda ancha, es decir

$$
\tilde{S}_{b}>\hat{S}_{b}>S_{b}
$$

Finalmente, la disminución del número de líneas activas disminuye el tráfico y el número de líneas activas aun más, y por eso también aumenta más el precio por minuto, vale decir

$$
\tilde{p}_{t}^{v}>\hat{p}_{t}^{v}>p_{t}^{v}
$$

${ }^{31} \mathrm{El}$ argumento que el precio de la banda ancha es muy alto y basta para remunerar al par de cobre nos parece inapropiado. Porque en el hipotético caso que la intensidad de la competencia en banda ancha fuera insuficiente, correspondería llevar el caso al Tribunal de la Libre Competencia, no corregir la supuesta distorsión con una intervención de precisión muy dudosa. 


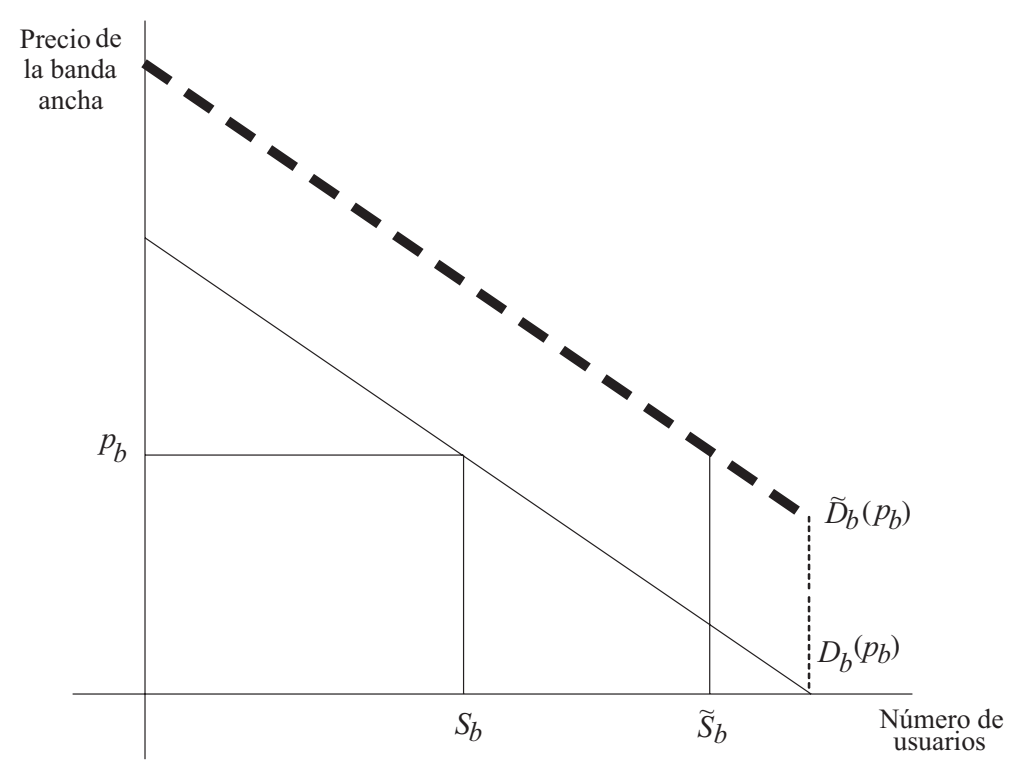

Nótese que ahora la telefonía IP sobre banda ancha podría penetrar aun si $p_{\mathrm{ip}}^{v}>\tilde{p}_{t}^{v}$, porque parte del cargo fijo de quienes emigren será pagado por quienes permanezcan en la red tradicional.

Podemos computar ahora el cambio de bienestar. Los $\tilde{S}_{b}-S_{b}$ consumidores que se conectan a la banda ancha para aprovechar la telefonía IP sobre banda ancha ganan

$$
\begin{aligned}
& H=\left(A+B+p_{t}^{f}-\tilde{p}_{\mathrm{ip}}^{f}\right) \times\left(\tilde{S}_{b}-S_{b}\right)+\int_{S_{b}}^{\tilde{S}_{b}} D_{b}^{-1}(\xi) d \xi-\left(m+c_{b}\right) \cdot\left(\tilde{S}_{b}-S_{b}\right) \\
& \equiv\left(A+B+p_{f}-\tilde{p}_{\mathrm{ip}}^{f}\right) \times\left(\tilde{S}_{b}-S_{b}\right)-\Delta^{d}
\end{aligned}
$$

en la Figura A2 (a). A éste se le suma el mayor bienestar que alcanzan los $S_{b}$ usuarios que ya estaban conectados a la banda ancha, y que alcanza a

$$
S_{b} \times\left(A+B+p_{t}^{f}-\tilde{p}_{\mathrm{ip}}^{f}\right)
$$


FIGURA A2: LA DEMANDA POR TRÁFICO DE VOZ CON TARIFICACIÓN “INCORRECTA”

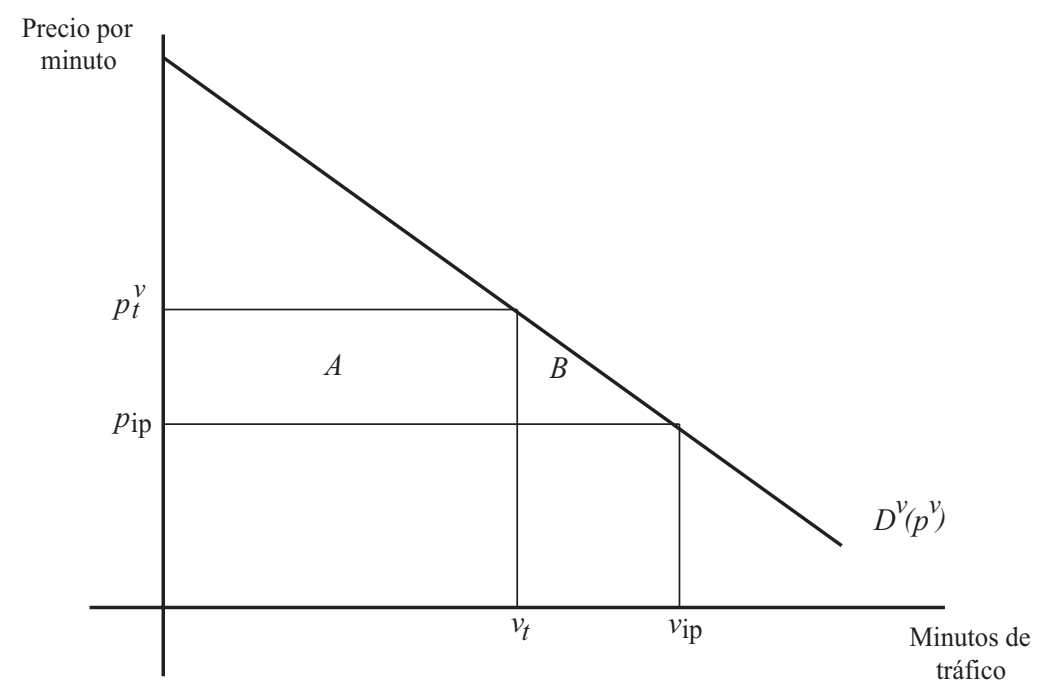

(a) Usuarios que emigran

hacia la voz sobre banda ancha

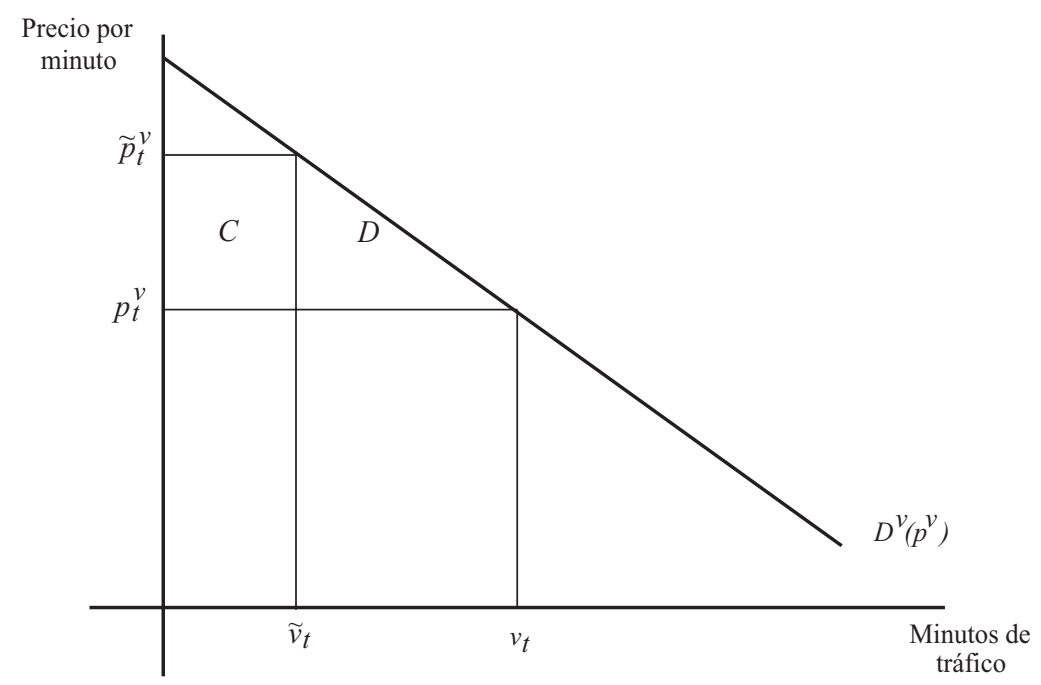

(b) Usuarios que permanecen en la telefonía tradicional 
Sin embargo, los $S-S_{b}$ clientes de la telefonía local que no se conectan a la banda ancha aun cuando sobre ella se pueden otorgar servicios de voz y ahorrarse parte del cargo fijo pagan aun más. Como se dijo, para asegurar el financiamiento de la red de telefonía tradicional con menos tráfico y líneas activas, el precio regulado por minuto debe aumentar desde $p_{t}^{v}$ hasta

$$
p_{t}^{v}=c_{t}^{v}+\frac{C_{t}^{l}\left(S-\tilde{S}_{b}\right)+F}{V_{t}}
$$

De manera similar a cuando la tarificación es correcta, el precio más alto por minuto reduce el bienestar de cada uno de $\operatorname{los} S-\tilde{S}_{b}$ clientes de la telefonía fija que no emigran a la voz sobre banda ancha en el área $C+D$ en la Figura A2, pero más. Y, de manera adicional, ahora el cargo fijo aumenta desde $p_{t}^{f}$ hasta

$$
\tilde{p}_{t}^{f}=\frac{\left[A_{t}(S)+C^{a}(S)\right]-\tilde{S}_{b} \cdot \tilde{p}_{\mathrm{ip}}^{f}}{S-\tilde{S}_{b}}
$$

Es decir, quienes no emigran a la telefonía IP sobre banda ancha pierden, además, $p_{t}^{f}-p_{t}^{f}$ de excedente. Así, la pérdida total de bienestar de estos consumidores es igual a

$$
\left(S-\tilde{S}_{b}\right) \times\left[(C+D)+\left(\tilde{p}_{t}^{f}-p_{t}^{f}\right)\right]
$$

Podemos enunciar ahora el siguiente resultado:

Resultado A.1. El cambio de bienestar debido a la introducción de la voz sobre banda ancha cobrándole menos a quienes migran a la voz sobre banda ancha es igual a

$$
\hat{S}_{b} \times\left(A+B+p_{t}^{f}-\tilde{p}_{\mathrm{ip}}^{f}\right)-\left(S-\tilde{S}_{b}\right) \times\left[(C+D)+\left(\tilde{p}_{t}^{f}-p_{t}^{f}\right)\right]-\Delta^{d}
$$

Es claro que también ahora el efecto sobre el bienestar es ambiguo. Pero quienes emigran hacia la voz sobre banda ancha ganan más que antes, y quienes permanecen en la telefonía tradicional pierden más. 
A.2 Los efectos distributivos cuando se tarifica "incorrectamente"

El Cuadro A1 repite el ejercicio reportado líneas arriba en el Cuadro $\mathrm{N}^{\circ}$ 6, pero esta vez supone que los usuarios que emigran a la voz sobre banda ancha dejan de pagar la red de acceso y los gastos administrativos. Por lo tanto, las tarifas de quienes permanecen (el cargo fijo y el cargo por minuto promedio) se ajustan para autofinanciar a la empresa eficiente. Para comparar, repetimos en cada caso lo que ya reportamos en el Cuadro $\mathrm{N}^{\circ} 6$.

La parte superior del Cuadro A1 muestra el efecto sobre los usuarios que no migran. Cuando sólo migra el 5\% del tráfico el efecto adicional no es tan grande, porque sólo migra el 1\% de los usuarios. Así, el cargo fijo aumenta desde $\$ 6.891$ hasta $\$ 6.938$, mientras que el cargo variable (promedio) por minuto sólo aumenta 5 centavos, desde $\$ 7,83$ por minuto, hasta \$7,88 por minuto. Así, el aumento del ingreso por línea cambia desde \$213 adicionales, si la tarificación es correcta hasta \$294 cuando la tarificación es incorrecta. Estos efectos son más grandes cuando emigra una fracción mayor del tráfico y de los usuarios. Si emigra el 15\% del tráfico (y el 3\% de los usuarios), el aumento del ingreso por línea cambia desde \$555 adicionales, si la tarificación es correcta hasta \$932 cuando la tarificación es incorrecta; mientras que el cargo variable por minuto debe aumentar a $\$ 8,67$, en vez de los \$8,41 cuando la tarificación es correcta.

La contrapartida de la mayor pérdida de quienes permanecen en la telefonía tradicional es una mayor ganancia de quienes migran. Relativo a la tarificación correcta, estos usuarios reciben ahora un beneficio adicional de \$7.152: \$3.065 por no pagar por la red de acceso y \$4.087 por no pagar los gastos administrativos.

La parte inferior del Cuadro A1 muestra el total del efecto distributivo cuando la tarificación es incorrecta. El monto total de las transferencias aumenta bastante. Si el 5\% del tráfico migra, quienes permanezcan deben pagar \$867,9 millones más al mes, contra \$626,7 millones si se tarifica correctamente. Y a medida que emigra más tráfico, el efecto es aun mayor: \$2.641,6 millones contra \$1.571,1, si emigra el 15\% del tráfico; y \$4.894,1 contra \$2.598,3 millones si emigra el 25\% del tráfico. Nótese que el menor aumento de la diferencia ocurre inicialmente. La razón, de nuevo, es que sólo unos pocos usuarios, aquellos de más alto tráfico, emigran en el ejercicio inicial. 
CUADRO A1: EL EFECTO DISTRIBUTIVO: TARIFICACIÓN “CORRECTA” E "INCORRECTA" COMPARADAS

Clientes / tráfico $\rightarrow$

99/95

$97 / 85$

$93 / 75$

Clientes que permanecen

Cargo fijo

$\begin{array}{llll}\text { C } & 6.891 & 6.888 & 6.970 \\ \text { I } & 6.938 & 7.104 & 7.462\end{array}$

Cargo variable por minuto

$\begin{array}{clll}\text { C } & 7,83 & 8,41 & 9,05 \\ \text { I } & 7,88 & 8,67 & 9,69\end{array}$

Total

$\begin{array}{llll}\text { C } & 12.090 & 12.085 & 12.228 \\ \text { I } & 12.171 & 12.462 & 13.091\end{array}$

Aumento de ingreso por línea

$\begin{array}{rrrr}\text { C } & 213 & 555 & 976 \\ \text { I } & 294 & 932 & 1.839\end{array}$

Clientes que migran

Ingreso por línea

$\begin{array}{rrrr}\text { C } & 16.979 & 14.791 & 13.722 \\ \text { I } & 9.826 & 7.639 & 6.570\end{array}$

Caída de ingreso IP

$\begin{array}{lrrr}\text { C } & 12.912 & 7.714 & 5.226 \\ \text { I } & 20.065 & 14.865 & 12.381\end{array}$

Efecto distributivo, tarificación

"incorrecta"

En millones de pesos

Caída de ingreso por línea (IP)

867,9

$\begin{array}{rr}2.641,6 & 4.894,1 \\ 2.225,1 & 3.974,6 \\ 416,5 & 919,5\end{array}$

Pérdida social

676,6

919,5

En dólares

Aumento de ingreso por línea (fijo) 1.592.491

$\begin{array}{rr}4.846 .976 & 8.980 .046 \\ 4.082 .301 & 7.292 .842 \\ 764.275 & 1.687 .204\end{array}$

Pérdida social

1.241 .389

351.092

764.275

1.687 .204 


\section{REFERENCIAS}

Chumacero, R. R. Fuentes y K. Schmidt-Hebbel (2004): “Chile's Free Trade Agreements: How Big is the Deal?”. Serie de Investigación No 264, Banco Central de Chile.

El Hureimi, N. (2005): "Excedente Social de la Telefonía sobre Internet en Chile, mimeo.

Galetovic, A. y R. Sanhueza (2001): “La Regulación de Cargos de Acceso Según la Ley General de Telecomunicaciones”. Informe encargado por VTR para ser presentado a la Subsecretaría de Telecomunicaciones.

Galetovic, A. y R. Sanhueza (2006): “La Economía Básica de la Telefonía Local”, mimeo.

Gasmi, F., J. J. Laffont y W. Sharkey (2002): “The Natural Monopoly Test Reconsidered: An Engineering Process-Based Approach to Empirical Analysis in Telecommunications”. En International Journal of Industrial Organization 20, 435-459.

Subsecretaría de Telecomunicaciones (2004a): "Regulación de los Servicios de VoIP”, documento de consulta.

Subsecretaría de Telecomunicaciones (2004b): Estadísticas de Desempeño del Sector de las Telecomunicaciones en Chile: Junio 2003 - Junio 2004.

Sutton, J. (1998): Technology and Market Structure. Cambridge: MIT Press.

Telefónica CTC Chile S.A. (2004): Comentarios de Telefónica CTC a la consulta pública sobre regulación de los servicios VoIP. Documento presentado ante la Subsecretaría de Telecomunicaciones. 